\title{
The capitalist mode of production
}

The capitalist economy in general: the production of monetary value and the enterprises' appropriation of surplus-value

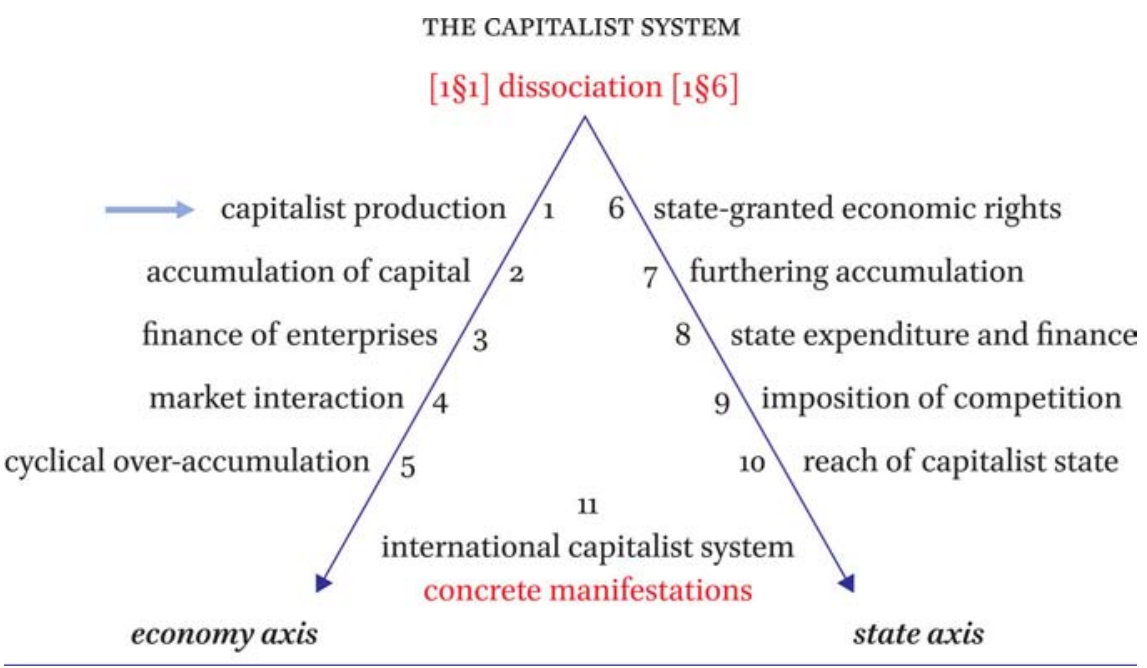

\section{Contents}

Introduction 29

Division o. Sociation - preparatory trans-historical notions $\quad 31$

1 §o Sociation: abstract conditions for social continuity 31

Division 1. Dissociation - outward bifurcation into households and privately owned enterprises 33

$1 \S 1$ Dissociated outward bifurcation into households and privately owned enterprises 33

Division 2. The monetary-value dimension 40

$1 \S 2$ The trade relation 40

$1 \S 3$ The value dimension: abstract general one-dimensional value 41

$1 \S 4$ The monetary-value dimension - market trans-abstraction and the requirement of money as the union of measure and medium of value 
Division 3. Commodification - the inward bifurcation of commodities 47

$1 \S 5 \quad$ Commodification of goods through their market transformation 47

$1 \S 6$ Commodification of labour-capacity and commodified consumption $\quad 5^{1}$

$1 \S 7$ Inward bifurcation of commodities: the commodification of inputs and outputs 'in total' 53

Division 4. Profit - duality dominated by the monetary-value dimension 54

$1 \S 8 \quad$ Profit as the monistic driving force of enterprises 54

Division 5. The capitalist production process - labour's productive power and the appropriation of surplus-value 55

Subdivision 5 A. The general form of the capitalist production process: duality of the production process and dominance of the monetary valorisation process 55

$1 \S 9$ The production process as technical process 55

$1 \S 10$ The production process as monetary valorisation process: inward bifurcation of the production process - ideal pre-commensuration $\quad 5^{6}$

$1 \S 11$ Dominance of the monetary valorisation process over the technical process: the inwarded drive for profit $5^{8}$

Subdivision ${ }_{5}$ B. Measures and determinations: surplus-value, capital as time-grasping investment, and the production of capital 6o

$1 \S 12$ The articulation of value-added and surplus-value (integral profit) 60

$1 \S 13$ Capital and time - the rate of integral profit and standard time 62

$1 \S 14$ Appropriation of the productive power of labour 65

Subdivision ${ }_{5}$ C. Grounding (sublation) of the dissociated outward bifurcation $\quad 76$

$1 \S 15$ The capitalist mode of production as solution to the dissociative 'provision of the material elements for survival' by enterprises $\quad 76$

Summary and conclusions $\quad 78$

List of figures chapter $1 \quad 81$ 


\section{Introduction}

As indicated in the General Introduction, this book aims to set out the capitalist system. Because a social system is inherently a series of interconnected institutions, relations and processes, it is not obvious at the outset of the investigation what should be the appropriate starting point of its exposition. The idea of a systematic-dialectical methodology is that one can best present a system in a layered movement that begins with general-abstract concepts of the (putative) system, gradually developing these into more concrete complex ones. ${ }^{1}$ At the same time, the starting general-abstract concepts should capture key characteristics of the system as a whole. In the systematic-dialectical methodology adopted in this book, the exposition also moves from absolutely necessary elements of the system to proximate necessities.

Given that I will be setting out a system, the status of the starting point in Division 1 is a relative matter. Chapter 1 in its entirety may be considered as the starting point. Given that production is absolutely indispensable for the material survival of any society, and considering that the historically specific form of production is a chief determinant of the totality, the exposition in this chapter starts with the specific capitalist form of production. This exposition is reached in the chapter's final Division 5 , where we will see that capitalist production essentially takes on the form of 'production of capital'. The earlier divisions provide the arguments as to why it takes on this form.

Apart from some preparatory ideas that are introduced in a Division numbered ' $\mathrm{o}$ ' (on 'sociation'), the formal starting point of this chapter is Division 1 (on 'dissociation'), which establishes that a key characteristic of the capitalist system is its structural-institutional separation between households and privately owned enterprises.

All of Chapter 1, and indeed the entire book, sets out how this separation is bridged within capitalism, and how the ways of bridging it often create new problems along the way. The first and major institution for resolving the separation is the market, a key element of which, as we will see, is that it homogenises heterogeneous products as one-dimensional monetary value (Division 2). The commodification that accompanies this process applies not only to nonhuman entities ('goods'), but also to the capacity to labour (Division 3). It is this two-fold trading - of commodities and of the capacity to labour - that

1 'Putative': although I will not repeat this term, the eventual proof that a 'system' is being presented is only delivered when all of the system has been presented - i.e. at the end of the book. 
SCHEME 1.1 The capitalist mode of production (outline

Chapter 1 )

[sociation - preparatory trans-historical conditions]

[1Do]

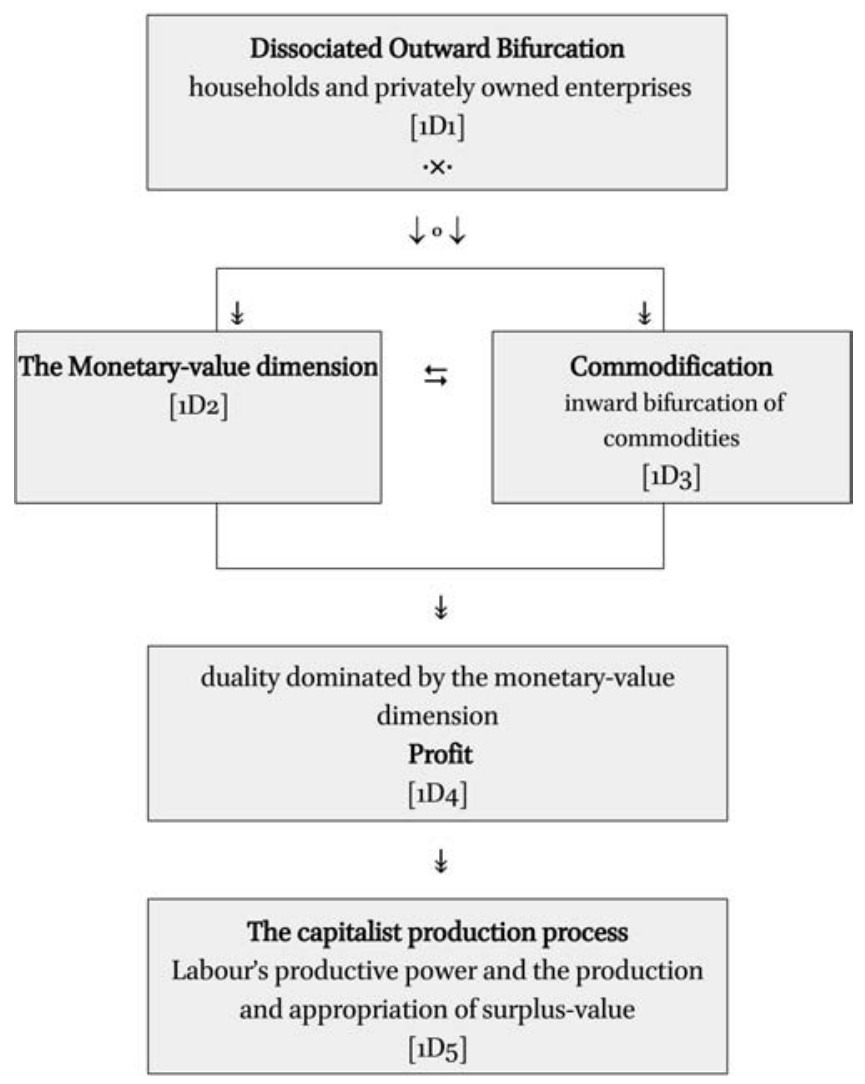

Legend

(the further meaning of the signs is explained throughout the chapter)

$\cdot \times$ continuity impediment

$\downarrow$ $\downarrow \quad$ sublated in (partially resolved in) *

$\downarrow \quad$ grounded in (conditioned by)

$\leftrightarrows$ dialectical mutuality **

* If at all, a full resolution is reached only at the book's end of the exposition.

** Dialectical mutuality: moments (here divisions) that presuppose each other. 
determines the particular capitalist drive for profit (Division 4), but foremost the profit-driven production process (Division 5). See Scheme 1.1 for the outline.

The starting point of this chapter will not prove to be difficult. Nevertheless, the first chapter will be the most demanding one for the reader. First of all it will be seen in Divisions 2-3 that although (or rather 'because') 'market trade in terms of monetary value' is an everyday phenomenon, adequately comprehending it is far from easy. Second, these same divisions, which are already difficult qua content, also constitute the reader's first significant acquaintance with the systematic-dialectical method adopted in this book.

Recall from the General Introduction that the text's systematic argument is offered in its main sections (shaded). The main text is usually followed by one or more 'Explications' that may be read according to need. Next to these there are 'Amplifications' and 'Addenda' that go into further detail or locate the argument within the wider literature. These are not part of the systematic argument and, in principle, the reader may forgo them if the main text is deemed sufficiently clear or uncontroversial.

For an explanation of field-specific and uncommon terms, the reader can refer to the Glossary at the end of the book.

\section{Division o. Sociation - preparatory trans-historical notions}

This Division sets out very general and abstract necessary socio-economic requirements that must be fulfilled for any imaginable society to be a potentially continuous constellation - be it a society organised along familial, communal, feudal, capitalist, socialist, cooperative or any other lines. These requirements are also what all imaginable societies have in common. It is possible to imagine a society in which the birth rate falls to zero, but such a society would no longer be continuous, and as such it does not fit the category of potentially continuous societies.

\section{$1 \S$ Sociation: abstract conditions for social continuity}

'Sociation' refers to the abstract minimum conditions that any imaginable society must meet in order for it to be a 'potentially continuous' social whole. Thus these conditions are trans-historical in that they apply to any concrete historical society.

Any such constellation requires social-human activities of creation, use and care of entities. ${ }^{2}$ The entities necessarily include food, shelter and clothing. The

2 Throughout this book the term 'entity' will be used in reference to 'a something' that has not yet been (fully) identified conceptually. 
potential continuity of the constellation requires that these activities include the procreation and socialisation of children. ${ }^{3}$

The creation of the entities entails a transformation of physical inputs into qualitatively divergent physical outputs. This transformation requires some combination of four elements:

- nature;

- human activity itself (the act of the transformative creation); this is predicated on the heritage of social knowledge, both formal and informal (tacit);

- cultivated nature;

- previously created entities as instruments.

All these conditions are abstract on two counts. First, in that these are formulated in terms of general concepts (trans-historically abstract). Second, in that these conditions do not set out the social relations through which these conditions are actualised (these are unique to a historically specific society).

$1 \S 0-\mathrm{a} \quad$ Explication. Sociation as a general and abstract trans-historical concept

Sociation refers to an abstract socio-economic totality. It merely posits the abstract concept of a system without showing how it is a system, that is, a potentially continuous social whole. What is more, the purpose of the concept of sociation is merely to refer to the historical phenomenon of systemic economies - or, in the terminology of Marx and Engels, 'modes of production'. For example, 'communal', 'patriarchal,' 'feudal' or 'capitalist' economies. The concept of sociation is trans-historical to the extent that it may be a preliminary entry point to the exposition of any systemic economy.

Herewith it should also be emphasised that the subject matter of the rest of this book - the capitalist system - is a historically specific, and therefore potentially finite, system. Early communal societies came to an end, systems of slavery came to an end, and feudalism is now, in the early twenty-first century, coming to an end throughout the world. It would be surprising if capitalism in some form - were to last forever. Nevertheless, much as a naïve university student may believe that today's knowledge will also be that of tomorrow, so naïve social actors may also believe that social history ends with capitalism. This could come to pass, but historically there are more reasons to believe that it will not.

3 Socialisation: the acquirement of language, skills, knowledge and norms.

4 The German Ideology, $1976\left[193^{1}, 1965 / 66^{2}\right]\{\mathrm{ms} .1845 / 46\}$. 
Some elements of capitalism emerged many centuries ago in one antediluvian shape or another. Key to capitalism as a system, however, is capitalist production, as combining monetary profit criteria for production and wagelabour as an input to production, which requires the existence of a labour market (systematically outlined in the current chapter). Capitalist production only gradually emerged from the end of the eighteenth century in England, Scotland and France, and at that time it existed alongside feudal production, which dominated in most countries of the North-West of the globe throughout the nineteenth century. However, in respect of Britain, the year 1846 (which saw the repeal of the 1815 Corn Laws) may be used as benchmark for the economic and political dominance of the capitalist over the feudal mode of production.

As indicated in the General Introduction, this book is not concerned with historical transitions. The empirical reference for the object of inquiry, and hence for Division 1 and the rest of the book, is roughly the type of economies as organised presently in the OECD, and more precisely those current OECD countries for which we have a reasonable amount of averages data from 1870 onwards.

\section{Division 1. Dissociation - outward bifurcation into households and privately owned enterprises}

Capitalist dissociation is conceptualised by four sets of 'bifurcations' (separations), each presented in this chapter. The first section presents the most encompassing one from which, as we will see, the other bifurcations derive as their conditions of existence.

\section{$1 \S 1 \quad$ Dissociated outward bifurcation into households and privately owned enterprises \\ $1 \quad$ Outward bifurcation into households and privately owned enterprises In capitalist society the 'activities' that are required for any sociation ( $1 \S 0)$ are generally institutionally separated, or outwardly bifurcated, into 'households' and 'privately owned enterprises'. In addition, these households and enterprises are generally non-self-sufficient and mutually dependent, whilst the enter- prises between them are also dependent on one another.}


Along with this bifurcation, the 'activities' take on particular forms - forms that are specific to the historically specific capitalist system.

The creation of entities $(1 \S 0)$ takes on the form of production at the site of enterprises. Regarding its requirements, the act of transformative creation of entities ( $1 \S 0)$ takes on the form of 'labour' as the distinctive activity of production. Of the other requirements, cultivated nature ( 1 §o) takes on the form of the privately appropriated earth whereas previously created instruments (1§o) take on the form of privately appropriated means of production - each appropriated by enterprises. Only free nature, that is, the part of nature that is not privately appropriated, does not take on a particular form (in the end, free nature is nature that cannot (yet) be appropriated - such as, hitherto, the sun, rain and wind).

The form of labour as the distinctive activity of production implies for workers that 'non-labour' takes the form of revitalisation and recreation at the site of households. (Revitalisation includes not only passive rest, but also various non-occupational individual or communal activities.)

Apart from formal education, all the other sociation requirements are located in households, where they take the forms of consumption or of housework, whilst the procreation of children has not generally taken on a capitalist form.

These forms are summarised in Table 1.2.

In capitalist society another major feature of the outward bifurcation is that in general enterprises are not owned by the labourers who carry out the production. Hence capitalist society is characterised by an extended outward bifurcation into the owners of private enterprises on the one hand, and the - generally non-overlapping - labourers carrying out the production on the other. Hence this outward bifurcation - rather than being an already far-reaching matter of 'mere' forms and locus of activities (Table 1.2) - is characterised by particular private property relations.

Along with these private property relations, the enterprise appropriates the product produced by labour - in whatever way, for what, and to what extent, labour receives a 'compensation' for its production.

$4 \quad$ 'Dissociated outward bifurcation' - reflection and preview

The starting point of the exposition so far ( $1 \S 1$ above $)$ reveals nothing spectacular, because it merely sets out condensed-abstractly how the capitalist economy

[continued] 
TABLE 1.2 Particular forms of activity pertaining to the outwardly bifurcated capitalist economy - specific to its mode of production

\section{Trans-historical sociation ( 1 §o) Dissociated outward bifurcation into households and privately owned General concepts enterprises $(1 \S 1)$ \\ Particular forms pertaining to the capitalist economy}

\section{Site of privately owned enterprises Site of households}

1. creation of entities

(transformation)

requiring:

- nature

- act of transformative creation

- cultivated nature

- previously created instruments
2. use of entities
3. care of entities
4. procreation of children

5. socialisation of children form of production

(here and below, for 'form of ...' read:

'takes on form of ...')

(free nature: no particular form) ${ }^{*}$

form of labour

(free nature: no particular form) form of non-labour: forms of revitalisation and recreation ${ }^{\dagger}$

form of privately appropriated nature

form of privately appropriated means of production

\begin{tabular}{|c|c|}
\hline & form of consumption \\
\hline & form of housework \\
\hline & procreation \\
\hline & (no particular form $)^{\ddagger}$ \\
\hline form of apprenticeship, or form of & form of housework \\
\hline production (formal education) $)^{\dagger \dagger}$ & (early education)㧊 \\
\hline
\end{tabular}

* $\quad$ Now mainly restricted to elements such as the sun, rain and wind.

$\dagger \quad$ Much of the recreation increasingly takes on the form of commodified consumption - row 2. (The term commodification is systematically introduced in $1 \mathrm{D}_{2}$.)

$\ddagger \quad$ When this book was completed, the procreation of children had not generally taken on a particularly capitalist form (even if various forms of commodification were emerging).

$\dagger+$ Part One yet abstracts from the State, hence also from state-provided education. Next to the form of apprenticeship, any other formal education then takes on the form of producing this education.

护 Much of the early education increasingly takes on the form of production (row 1) and consumption (row 2) - e.g. 'day care'.

Later on the terms of 'increasingly' (under † and $\ddagger \ddagger$ ) will be conceptualised as 'tendencies'.
$1 \S 1 \quad$ Continued
appears in empirical reality. However, the starting point does not reveal how
it can have 'existence in' concretely interconnected relations between these
households and enterprises. (For example, via what relations does labour get 
from households to enterprises, via what relations is production carried out, and via what relations does the product of enterprises reach households?) Given that a form of material 'production' (generally: transformative activity) is indispensable for the survival of any society, the capitalist outward bifurcation into households and privately owned enterprises appears as dissociated and hence highly problematic.

This constellation is posited as dissociated, even if we know that in reality the bifurcated poles are in some way bridged. The object of the exposition in this book is to comprehend both the range of this dissociation and the extent of its actual resolution.

Therefore, the remainder of this chapter presents the first and elementary stages of the conditions of existence of the starting point outlined above. To this end, it presents the first stages of the capitalist economy's way of 'sublating' the outward bifurcation (that is, stages of partially resolving the bifurcation without the bifurcation itself being undone - see Explication $1 \S 1-a)$.

Pending the complete exposition of these conditions of existence, the entirety of the outward bifurcation presented above - including its forms and property relations - is referred to as 'dissociated outward bifurcation'. Pending the complete exposition, this bifurcation is as yet an 'impediment' to the continuity of the capitalist economy.

1§1-a Explication. The terms 'sublation' and 'grounding' The term 'sublation' refers to the (initially) partial resolution of a major impediment, without that impediment itself being undone. In this book this is the impediment posed by dissociated outward bifurcation. These partial resolutions, though increasingly less partial, are presented in the rest of this chapter, and the several stages of this book in its entirety. A full resolution is only reached, if at all, at the end of the exposition. The term sublation is mainly used in Chapters 1 and 6. For the rest (and already in these chapters) I simply use the term 'grounding' (a series of grounding throughout the book), that is, the grounding of the outward bifurcation posited at the starting point ( $1 \S 1)$. Grounding is the same as the determination of a (partial) condition of existence of the outward bifurcation.

\section{1§1-b Explication. Logical systematic exposition}

Systematic dialectics investigates systemic constellations, in our case that of capitalism. It does not investigate transitions towards that constellation from a previous one (as in a historical dialectic). Therefore the bifurcation and dissociation posited in $1 \S 1$ should be understood as logical, not historical. (A similar remark applies to all the sections to follow in this book.) This bifurcation is 
posited as the general-abstract reference to the current capitalist system, and its economy in particular.

1§1-c Explication. 'Dissociated outward bifurcation' and the initial reference to the capitalist totality

Although dissociation refers to the capitalist totality, it is no more than an initial reference. As we will see, it is the mode of resolving (i.e. sublating) this bifurcation, and the contrarieties deriving from it, which characterises the capitalist system.

The outward bifurcation as posited in $1 \S 1$ is both simple and complex. It is simple insofar as we all know that there is this institutional separation between households and enterprises (this is also the first lesson of mainstream microeconomics). It is complex, as we will see, because the ways of resolving this separation are far from evident. Even if we 'know' the constellation in terms of this separation, it cannot exist without a mode of sublating that bifurcation. Hence, posited as such, that is, without any connections between the bifurcated poles, it is an impossible constellation because it (still) lacks the conditions for its existence, the grounds for its existence.

We will see that each effort at sublation (at least until we reach the end of the exposition) poses new problems, thus revealing this sublation as being yet insufficient and so requiring further sublation. Hence, each time the exposition of the system is driven forward by the 'insufficiency' of the moment or moments posited at the earlier level of the exposition. (See $1 \S 1$ - $d$ for the term 'moment'.)

$1 \S 1$-d Explication. The meaning of 'moment'

Consider Scheme 1.1. Each division of the current chapter and of later chapters is indicated as a 'moment' (sometimes the term also applies to the separate sections of a division). A 'moment' is a more or less cohesive institutional make-up (at a more concrete plane one may think, for example, of 'the labour market' or 'banking'), or a more or less cohesive set of entities, that can be analysed by itself (sometimes like a model) but that nevertheless derives its full meaning from its interconnection with other moments, and ultimately from its interconnectedness within the whole exposition. Thus moments derive their full meaning through synthesis. ${ }^{5}$

In respect of the current chapter, for example, the moment of outward bifurcation ( $1 \mathrm{D} 1)$ is first sublated in the moments of monetary value and commodification $\left(1 \mathrm{D}_{2}-1 \mathrm{D}_{4}\right)$. Their insufficiency prompts the introduction of the moment of capitalist production $\left(\mathrm{I}_{5}\right)$ into the exposition.

5 See also Reuten and Williams 1989, p. 22, where this is framed rather more dialectically. 
1§1-e Amplification. The term 'general' in 1§1: the general and predominant character of the capitalist dissociation

I always adopt the term 'generally' to refer beyond contingencies that are compatible with capitalism, whilst, if those current contingencies were to be generalised, there would no longer be capitalism. (Take two simple examples: contingently a pair of people may not be able to have children; however, if this were generalised, then humanity would come to an end. Similarly - in reference to the end of this chapter - contingently capitalist enterprises may not make profits, but if this were generalised, then capitalism would come to an end.)

The capitalist economy is characterised by the outward bifurcation between households and privately owned enterprises. In $1 \S 1$ I used the term 'generally' on a number of occasions in reference to the outward bifurcation between households and privately owned enterprises that characterises capitalism. However, this does not exclude the fact that, contingently, there are households to which the separation does not apply - even if the non-dependence on other units (i.e. enterprises) is rare within full-fledged capitalism. Similarly, regarding the property relations it is far less rare, though again contingent, that - now within the outward household-enterprise bifurcation - one or more members of a household run a business (in economics this is often called 'independent' or 'self-employment') without employing labour.

In this book I refrain from characterising the type of economy that would exist if there were a market economy with generalised self-employment or generalised workers' cooperatives or a combination of the two (Smith 2017, ch. 12, is very thought-provoking on this).

1§1-f Amplification. The terms private ownership and possession The full meaning of 'private ownership' will only become explicit in Chapter 6 (that chapter introduces the state's granting of 'legal property right', which is a major condition for the dissociation). In Part One (still abstracting from the State), 'possession' (actual physical control of an entity) and 'ownership' are used in a broad sense. In this usage, the term ownership in particular bears no explicit or implicit reference to 'title to legal right' and thus a possible legally recognized ownership.

1§1-g Addendum. Separation, dissociation, labour: references The separation of the units of production from the units of consumption is also stressed by Weber (1968 [1920], p. 21): 'The modern rational organization of the capitalist enterprise would not have been possible without ... the separation of business from the household, which completely dominates modern 
economic life .... The insight of the separation of 'activity' into productive and consumption activity derives from Himmelweit (1984). The term 'dissociation' is also used by De Vroey (1981, p. 176) Eldred, Hanlon, Kleiber and Roth (1984, p. 354), Reuten (1988), Reuten and Williams (1989) and Smith (2017).

\section{1§1-h Addendum. Marx's starting point in Capital}

In Capital Marx's starting point is 'the commodity' (Volume I, Chapter 1). On the one hand, this refers to everyday perception. ('The wealth of those societies in which the capitalist mode of production prevails, presents itself as "an immense accumulation of commodities"' - the opening of Marx's Capital). On the other hand, the commodity is the initial abstract resolution of the dissociation problematic - as we will see in $1 \S 4-1 \S 7$. Thus, in a way, Marx starts with the 'abstract perception' of the initial resolution. If so conceived, Marx's starting point may not be fundamentally different from the current one.

1§1-i Addendum. Dissociation: no 'falling apart' vis-à-vis sociation This book adopts a development from a Hegelian-Marxian systematic dialectic. Both Hegel and Marx also adopted a historical dialectic (General Introduction, Appendix). ${ }^{6}$ From a Hegelian historical dialectic point of view it might be tempting to conceive the 'dissociation' in terms of a 'falling apart' vis-à-vis 'sociation' (see Plant 1977, on 'falling apart' and reconciliation). For the current systematic dialectic, however, 'sociation' is not an ideal but rather an abstract concept, of general requirements, without the social relations through which these conditions are actualised. Hence 'dissociation' cannot be a falling apart relative to 'sociation'. The dissociated outward bifurcation just aims to refer to the totality of the capitalist system.

$1 \S 1-\mathrm{j} \quad$ Addendum. 'Contradiction' - dissociation as a contradictory constellation

In the main text I have avoided - and will avoid henceforth - the dialectical term 'contradiction' mainly because expounding it would require a disproportionate amount of space relative to the insight that it might provide. For the purposes of this book I can do with the term 'continuity impediment'. Here I nevertheless provide a brief inkling. The dissociated bifurcation as posited in $1 \S 1$, that is, without particular interconnections between households and privately owned enterprises, it is apparently impossible, it can have no existence, it is in itself contradictory. Hence, posited as such, it is a contra-

6 See also Murray 2003. 
dictory constellation because it (still) lacks the conditions for its existence, the grounds for its existence. Thus a contradictory entity or a contradictory constellation is one that cannot exist in the absence of particular conditions or grounds. In systematic-dialectical works these are most often referred to as sublations, which each time reveal new defects that require further sublation (see Inwood 1992, pp. 63-5, 283-5 and $115^{-16}$, for a brief expounding of the terms of 'contradiction', 'sublation' and 'ground' in reference to Hegel's works).

\section{Division 2. The monetary-value dimension}

This division presents the first moment of the particular way in which the capitalist economy resolves the dissociated outward bifurcation.

\section{$1 \S 2 \quad$ The trade relation}

The continuity impediment of the dissociated outward bifurcation $(1 \S 1)$ is apparently resolved in trade relations. Trade potentially connects households and enterprises.

In the current division, trade is considered from the perspective of enterprises. It is pre-posited that enterprises dispose of labour-capacity (presented in Division 3). The production process is also pre-posited (presented in Division 5). Hence the current division considers trade in terms of the inputs and the outputs of production.

1§2-a Explication. Abstract trade

The idea that dissociated outward bifurcation $(1 \S 1)$ - in whatever particular type of conceptualisation - requires some form of trade is nothing new. It has been a key issue in political economy and economics from Adam Smith's (1776) 'invisible hand' to the Arrow and Debreu's (1954) 'general equilibrium theory'.

However, the trade relation posited in $1 \S 2$ is utterly abstract: especially the form of the trade relation has not been determined. The trade relation is merely the first condition of existence of this dissociation. However, this cannot be turned around: trade does not necessarily imply capitalist relations. Generally, trade in the abstract is compatible with a multitude of trade criteria, including, e.g., quid pro quo labour time, and reciprocal need. 
1§2-b Explication. Note on the following sections $(1 \S 3-1 \S 5)$

The following three sections posit 'value', 'money' and the 'commodity'. Classical Political Economy (Smith, Ricardo, Mill), as well as Marx, start their treatment of value by observing that in practice we have the duality of 'use-value' (usefulness) and 'exchange-value' (the latter is what they call, in brief, 'value'). Instead of just observing this, the following three sections ground this duality. While these sections might prove difficult, the reader is advised to keep in mind that this duality is just grounded. It must be grounded because this duality is crucial to the capitalist system, and decisive for much of what follows in the chapters to come.

\section{$1 \S 3$ The value dimension: abstract general one-dimensional value}

The outward bifurcation $(1 \S 1)$ not only requires the trade relation $(1 \S 2)$, but also determines the latter's character, that is, the capitalist social form, the social dimension, of the trade relation.

Physical inputs to processes of production qualitatively diverge from the physical outputs. The dissociated outward bifurcation $(1 \S 1)$ entails that the physical product of enterprises is generally not destined for its producers. If enterprises and households were not bifurcated, then the physical divergence might generally be the aim (food, shelter, clothing, etc.). However, when an enterprise produces, e.g., laces only, then the use of laces by the producers is not the immanent aim. The dissociated outward bifurcation entails that the driving force of enterprises must be an aim other than the physical entity produced - an aim external to the physical product.

Hence the processes of production and trade necessarily require inputs and outputs to be reduced to a homogeneous common denominator. Therefore the capitalist social form of the trade relation is necessarily one of absorption into and reduction to a common denominator. One-dimensional abstract value is the sui generis of this homogeneous common denominator. Value must be constituted as general value as opposed to the particularity and specific usefulness, or specific multifaceted characteristics, of the physical input and output. Thus abstract generality, one-dimensional general value, absorbs concrete specificity. In other words, the particular products of particular labour necessarily have to take on the general form of value; without them being validated as such, they are socially non-existent. ${ }^{7}$ As such, value as social form is the necessary dimension of the entities produced by labour in a dissociated mode of production.

7 At this point 'validation' just refers to 'valid'. From $1 \S 4$ onwards it will, more specifically, mean the turning of outputs into money. 
Henceforth the term 'value' is used as shorthand for 'abstract general, onedimensional, value'.

1§3-a Explication. Value as social dimension

In everyday language 'value' often has a multifaceted meaning. ${ }^{8}$ Within the economic domain it has one-dimensional meaning. One-dimensional value is tied to specific social constellations, thus it is a historically specific social concept. As a social dimension 'value' is not an a priori (in Kant's sense) natural-physical dimension nor is it universal (space and continuity), although value is a category as abstract as space and continuity. Note that at the current level of the exposition (1§3), the concept of value is near to empty. Concepts such as measure of value will be introduced in the next section. The point is that the positing of any form or dimension (in this case that of value) should precede that of its measure(s) and standard measure(s).

\section{1§3-b Amplification. Specific usefulness}

The main text states: 'Value must be constituted as general value as opposed to the particularity and specific usefulness, or specific characteristics, of the physical input and output'. Up to this point in the text it may have seemed that 'one-dimensional abstract value' might include the Marginalist and Neoclassical concept of 'utility'. However, that concept is meant to capture subjective 'use-value', which is the opposite of the concept of value at hand. The latter connects rather with the Classical concept of 'exchange-value' - one that these economists indeed opposed to 'value in use'. (Cf. Smith 1776, Book I, Ch. 4, section 13). This issue will be further articulated in sections $1 \S 4$ and $1{ }_{1}$.

1§3-c Addendum. Value and measure of value in marxian theory Within the marxian tradition to this day, there has been quite an important penchant for turning 'immediately' from the concept of value to a, or 'the', measure of value, and to take the two as identical. Labour-time is often supposed to perform this two-in-one job (in fact this error of moving too fast stems from Ricardo $\left.1981\left[1817^{1} ; 1821^{3}\right]\right)$. More details are set out in Reuten (1999a).

8 When the Dutch poet Lucebert wrote: 'Alles van waarde is weerloos' (everything of value is defenceless - in 'De zeer oude zingt', published 1974), he obviously did not refer to stocks or similar financial assets. The nineteenth-century philosopher Rudolf Lotze imported the 'economic' concept of value from political economy into philosophy (Stirk 2000, p. 16o; Nauta 1980 [1971], p. 104). From there the term was imported into sociology where it is key to the conceptualisation of social formations. 
Note: The reader may be warned that the next two main sections $(1 \S 4$ and $1 \S 5)$ are more demanding than any other in this chapter and, indeed, in the entire book.

\section{$1 \S 4 \quad$ The monetary-value dimension-market trans-abstraction and the requirement of money as the union of measure and medium of value} The interplay of the trade relation $(1 \S 2)$ and the reduction to a common denominator, i.e. the absorption into abstract general, one-dimensional, value $(1 \S 3)$ is constituted in the market.

Actual market trade: commensuration as abstraction in practice

Prior to the trade act in the market, the buyers assess the heterogeneous useful characteristics of the entities brought to market, whilst the sellers sing their praises (and perhaps try to hide an evil trait). In the end, however, upon the actual market trade, heterogeneous entities are made commensurate in terms of something that is no part whatsoever of their concrete physical bodily form or concrete constitution. We have a trans-abstraction in practice: the alien dimension of 'value' is ascribed to the entity, or rather it is vested in the entity. ${ }^{9}$

Money as measure of value

So far $(1 \S 3)$ the conceptual focus on value has been qualitative, dimensional. Market trade of entities, however, takes place in specific quantities of the quality posited. This necessarily requires measurement and a measure for the quality of value. The value trans-abstraction at the market operates through money. Put more strongly, money is a necessary condition of existence of onedimensional value. The first requirement for something to be money is that it can be a measure of value.

\section{$3 \quad$ Money as medium of value}

Nevertheless, the measurement in terms of money (perhaps in a value-assaying procedure between seller and buyer establishing that some price is appropriate) does not determine the value quantity of the entity. Value, a fortiori value quantity, does not exist without actual market trade, and money as actual medium of quantity of value. With the actual market trade the value assaying procedure, the measurement, is no longer without commitment. Thus actual market trade is the value salto, the value leap - the telling ( hic est) is not enough:

9 The term 'trans-abstraction' is expanded upon in $1 \S 4$-b. In brief: a trans-abstraction in practice is not an abstraction of the mind that sorts or grasps sensuous phenomena, but rather the result of action, i.e. of social intercourse. 
hic saltus. ${ }^{10}$ Hence the second requirement for something to be money is that it is a quantitative medium of value.11

Because, and to the extent that, (some) money acts as medium of value in market trade, and so proves and reproves itself, it can be an effective measure of value. ${ }^{12}$ Thus money is the necessary unity of measure and medium of onedimensional value.

\section{Standard measure of money}

So far the matter of standard measure has not been alluded to. In comparison with the issues presented so far, it is secondary and uncomplicated. Suffice it to posit that generalised market trade requires a standard or convertible standards of money (e.g. dollar, yuan or euro). Then, in terms of some standard measure (e.g. $€$ ), entities are grasped in terms of a number (e.g. $€_{12}$ ) that we call price. Thus the price of an entity is its monetary value as expressed in a particular standard.

6

Money: no inherent content, no inherent value

Unlike the entities that money measures, money has no inherent content neither bullion, nor paper, nor electronic pulses; even if some particular shape of money may be more adequate than another (amplified in $2 \mathrm{D}_{4}$ ). Consequently, money has no inherent value. Money is inherently merely a quantifier of one-dimensional value. ${ }^{13}$

10 Salto (jump) refers to Marx's phrase about the crucial 'jump' in exchange of the commodity into money (Capital I, Ch. 3, Section 2-a); the hic est (this is; 'this is my body') refers to the consecration in the Catholic Mass (a much neglected metaphor used by Marx in a similar context - see Reuten 1993, p. 97); the hic saltus (thou should jump here) refers to Hegel's phrase in the Preface to his Philosophy of Right (1967 [1821 1$]$ ) in reference to a boastful person who is invited to demonstrate his tricks here and now.

11 This is notably different from the misleading neoclassical notion of money as 'medium of exchange' (see $1 \S 4-c)$.

12 To the extent that money proves to be an effective medium of value in market trade, it is reinforced as an effective measure. The two are mutually reinforcing.

13 Money measures and mediates value but it has no value in itself. This applies for capitalist money (as further grounded in $2 \mathrm{D} 4$ ). (For the time being, the following may perhaps help. A metre-stick measures length and has itself relevant length. However, an electronic scale or a spring may measure weight without them having the relevant weight.) 


\section{Value and the Monetary-Value Dimension}

Because value is a super-sensuous dimension and, as such, utterly abstract that is, abstract in practice - and because it is in daily practice known only through the money medium, it is in daily practice identified with 'value as measured by money'. That is, value is in mundane practice identified with 'monetary value' as a hypostatic union of dimension and medium. ${ }^{14}$ Even further, in mundane practice money may not be perceived as 'medium' but, hypostatically, as being value itself.

Nevertheless, even in that perception value and money are not seen to be identical (as in 'value $\equiv$ money'). Something may be ascribed 'monetary value' without being money. Indeed this is what happens outside the market when some monetary value is ascribed to entities (for example, a building, a machine or a pen). Again, as with abstract value, this monetary value is super-sensuous in that it is no sensuous characteristic of the entity (amplified in 1§10). This conception in practice is captured by the term Monetary-Value Dimension (MVD).

1§4-a Explication. Pre-posited money creation

The main text posits the abstract concept of money - that is sufficient for the rest of this chapter. It pre-posits the actual creation of money by banks, which is presented in Chapter $2\left(2 \mathrm{D}_{4}\right)$.

\section{1§4-b Explication. Abstraction and 'trans-abstraction in practice'}

Generally an abstraction is considered to be a mental act. There are at least four types of mental abstraction, of which the first three have overlapping aspects. The first posits abstract generality as opposed to concrete specificity (this is the common usage of the term in this book - see the Glossary for further explanation). In the second type, various elements of reality are (temporarily) neglected so as to focus on one or several elements that are thought to be key to a certain realm of reality, or perhaps all of reality. In the third type, the same aim of focusing is reached by way of the reduction of the various elements of reality to known common elements or categories. In the fourth one, we have a reduction to hitherto unknown common elements or categories. Although processes of abstraction are engrained in our common language, they are part and parcel of the sciences in particular.

14 The term 'hypostatic' is a metaphorical reference to Christianity for which God is much too abstract, so that a human being, Christ, mediates between God and (other) human beings. Nevertheless the human being Christ acquires divinity. This double identity is called hypostasis. By analogy value is too abstract, and as such it must be mediated by money; even further: in everyday practice money and value are often seen as identical. 
However, there are also abstractions that do not (primarily) evolve as mental acts but rather in the practice of life - and especially in economic life. The exemplary case is the actual reduction of entities at the market to a monetary denominator. I call these abstractions in practice (cf. Reuten and Williams 1989, pp. 62-4). (In fact one reason why economics, in comparison with other social sciences, has a much easier job in quantifying elements of its domain is that the domain itself produces key abstractions as well as key measures for them compare, for example, 'power' in political science for which the scientist has to devise measures.)

The main text of $1 \S 4$ states: 'upon the actual market trade, heterogeneous entities are made commensurate in terms of something that is no part whatsoever of their concrete physical bodily form or concrete constitution ... the alien dimension of "value" is ascribed to the entity, or rather it is vested in the entity'. If the dimension of value, like perhaps that of mass, were one physical aspect of the entity, then we would have an 'actual abstraction in practice' which already would be remarkable enough. However, it has been emphasised that value is in fact a dimension alien to the entity. Thus the abstraction that is performed in the market is in fact super-sensuous, or transcendental - whence I adopt the term trans-abstraction. In the market, at the point of trade, sensuousness is installed by the money mediator. But beyond the point of trade this sensuousness vanishes into super-sensuous monetary value.

As we will see in Division 5 and in Chapters 2-3, the sensuousness of the money mediator does not absolve us from the concept of value: most of the time, especially during production, and always when non-money assets are at stake, economic entities are supposed to 'have' value - that is, super-sensuous monetary value - in the absence of the money mediator's act. When money comes in - in acts of trade - money makes us at least nearly touch on value, much like in various religions wherein the prophets allow believers to feel closer to God.

We need an uncommon language (trans-abstraction in practice) because we are dealing with - as far as I can see - the most complicated part of the capitalist economy and of all of the sciences of political economy and economics.

1§4-c Explication. The misleading notion of money as 'medium of exchange'

The reader may have noticed that from 1 \$2 onwards I have used the term 'trade', not 'exchange'. The latter has often (also) a connotation of barter. Indeed many discourses of the capitalist economy start with notions of barter (and some remain somewhat enmeshed in it). The main text $(1 \S 4)$ introduced the concept of money as 'medium of value' $\left(C_{i} \leftrightarrow \mathrm{M}\right.$, where $C_{i}$ indicates commodity i, M 
money and $\leftrightarrow$ transfer). Herewith I distance myself from the orthodox economic concept of money as 'medium of exchange' (which would be $C_{i} \rightarrow \mathrm{M} \rightarrow C_{\mathrm{j}}$, where $C_{j}$ indicates commodity j). The latter term carries implicit or explicit notions of barter exchange $\left(C_{i} \leftrightarrow C_{j}\right)$, with just the non-coincidence of wants evaded. ${ }^{15}$ In that orthodox view money is of subordinate importance: money as medium of exchange is merely more efficient. However, no systematic barter exists in capitalism. Market trade always takes the form of $C_{\mathrm{i}} \leftrightarrow \mathrm{M}$; so money is a medium of value and never a medium of exchange. ${ }^{16}$ The watershed between the two concepts (medium of value and medium of exchange) is the valuedimension (i.e. the value-form). The orthodox terminology implicitly neglects that there might be a dimensional problematic at all.

1§4-d Addendum. The term 'actual'

Throughout this book I use the term 'actual' not in Hegel's sense, but rather in reference to existence.

\section{Division 3. Commodification - the inward bifurcation of commodities}

As indicated, Divisions 2 and 3 are posited at the same level of the exposition and presuppose each other (dialectical mutuality).

Note: From the next section onwards, the sections will often start with a brief summary statement that is indented.

\section{$1 \$ 5$ Commodification of goods through their market transformation}

Trade $(1 \S 2)$ concretised as actual market trade in terms of money - the unity of measure and medium of one-dimensional value $(1 \S 3-1 \S 4)-$ potentially constitutes the inputs and outputs of enterprises $(1 \S 1)$ as a determinate magnitude of one-dimensional monetary value $(1 \S 4)$.

15 The motive for a bicycle producer might perhaps be the purchase of a car or perhaps to make a saving. None of these motives makes money a medium of exchange.

16 A term that is at least on the edge of being problematic is that of 'medium of circulation', one that was unfortunately also used in Reuten and Williams 1989 (for which I take responsibility). It may be noted at this point that for Marx $(1867$, Ch. 3$)$ money's two main 'functions' are that of 'measure of value' and 'medium of circulation' (alongside means of hoarding and means of payment). Medium of value versus medium of circulation is not just a terminological difference; the former posits a concretisation of value that is (at least) less obvious for the latter. 
The actual market trade operates through the discrete money medium as quantitative medium of value. Money is the quantifier through which value appears, and is perceived as reflected onto entities. Through the money medium the trans-abstraction of value at the market concretely appears as a reflected transformation of entities - henceforth the 'market transformation of entities. ${ }^{17}$ Hence the entities appear in a dual guise, an inwardly bifurcated guise: that of their physical shape and that of reflected value. This inward bifurcation constitutes entities as commodities. Thus commodities have a dual character: their physical make-up and their value reflected through money. This transformation and hence this duality applies to goods, including good-like services (services that for their production require material inputs).

1§5-a Explication. The market and monetary value as 'too normal' phenomena

The main text of $1 \S 3-1 \S 5$ is key to this book. Implicitly it aims to answer the question 'what is value?'. Note first that an answer along the lines of 'costs' is circular insofar as costs, presumably, are in the same dimension. If costs were in a different dimension - as in classical labour theories of value - we would run into a regress because we would still have to make a jump, a transformation, from, say, labour-time to value. (In some varieties of marxian theory - but not in Marx's - the problem is polished away by just reducing value to labourtime - I briefly return to this in $1 \S 5^{-\mathrm{d}}$ and e). If the answer were given in terms of heterogeneous 'preferences' (as in neoclassical theory), equally we would encounter a regress to the extent that preferences have to be transformed into the value dimension.

It is not obvious that entities acquire a social dimension that is alien to their physical make-up. At the same time the problem of comprehending market trade in terms of value, and of responding to the question of 'what is value', is so complicated because we are hindered by the fact that it is overwhelmingly part of our everyday experience and so it seems 'too' familiar. Each day the sun rises in the morning and sets in the evening. Why think about it? Well, we know that this rising and setting is a false appearance, even if we ignore this in our language and experience. You buy a loaf of bread in the morning and a beer in the evening by tossing some coins on the counter or inserting a smart card in a slot. It happens every day. Why ruminate on this further?

17 This complex 'reflected transformation' is to be distinguished from the so far relatively simple 'transformative creation of physical entities' (in capitalism taking the form of production) - as alluded to in $1 \S 1$. 
The point is that the forces engendered by the monetary-value dimension overwhelmingly determine our lives. At the same time these are not inevitable facts of nature, but rather the result of our own political-economic doing. ${ }^{18}$

1§5-b Addendum. Inwardly bifurcated commodities: notes on the history of economic theory

I have dedicated quite a lot of space $(1 \S 2-1 \S 5)$ to the task of positing the inward bifurcation of commodities. Classical political economists (CPE) such as Adam Smith (1776, Book I, Ch. 4, section 13) and David Ricardo (1981 [1817 ], Ch. 1, section 1), without much ado, simply mention the duality (internal bifurcation) as a fact of life, merely to delineate that political economy is about 'value in exchange' rather than 'value in use.' Thus although these economists are aware of the two aspects of the commodity, they do not problematise it and reduce their discourse de facto to exchange-value (in short, also for them, 'value').

Neoclassical economists neglect the issue by reducing value to use-value (utility). As a consequence they are forced to treat money as some strange appendix to the science of economics: prices are utility determined (or preference determined) barter 'prices' (in fact barter ratios). Then, via the 'good' that happens to be a handy medium of barter exchange, i.e. 'money', the general price level is determined by a Quantity Theory of Money. Apart from the determination of the price level, money does not matter. $\left.{ }^{19}\right|^{20}$

Although Keynes (1936) - as well as current post-keynesian economics - is a leading critic of the neglect of money in neoclassical economics, his point of application is not - what we now call - microeconomic issues and the market as such, but rather the macroeconomic aspects of money. When dealing with these in Chapters 2-3, I will return to Keynes.

18 More specifically, our own political-economic doing in the sense that Marx expressed it: 'Men make their own history, but they do not make it just as they please; they do not make it under circumstances chosen by themselves, but under circumstances directly encountered, given and transmitted from the past. The tradition of all the dead generations weighs like a nightmare on the brain of the living' (Marx 1979 [1852 $2^{1}$, p. 115).

19 It is rather impractical to deliver a university diploma in economics stamped with the message that money does not matter; so economics departments deliver an appendix course on 'money, credit and banking' setting out some nasty details of the matter - the main economics courses can do without this. (In a critical essay, Frank Hahn (1981), a prominent proponent of General Equilibrium Theory, set out the limitations of (this) neoclassical economics.)

20 Twisting the matter Milton Friedman (e.g. 1959 or 1968) argued that 'money matters' because it determines the price level. 
What Marx calls the two-fold character of the commodity is key to his Critique of Political Economy [1859] as well as to the first 10o pages or so of the first Part (Chs. 1-3) of Capital, Volume I [1867'] where he uses the terms 'double character', 'two-fold character' and 'duality' of the commodity as synonyms. Marx's way of proceeding is somewhat different from the one presented above. He starts from the commodity and commodity trade (exchange) and derives the commodity's duality from it, before expanding on value and finally arriving at monetary value. Above I started with the dissociated outward bifurcation (which remains implicit at Marx's starting point), then introduced the trade relation, value and monetary value and finally arrived at the commodity and its duality that I posited as an inward bifurcation $(1 \S 5)$. (Bifurcation is a translation of the German 'Entzweiung'). ${ }^{21}$

1§5-c Addendum. Marx on money as the measure of value Because Marx's Capital - as much as the current book - adopts the method of systematic-dialectical immanent critique, it is not surprising that when discussing the concept of value in the first chapter of that book, he starts off from the received view of his day. Namely that of Classical Political Economy, which posits - in several varieties - a 'labour theory of value' (in brief: labour is the source of value - see e.g. Reuten 1999a and 2018a). He assumes that the reader is familiar with this (at the time) mainstream view. However, a present-day reader might believe that Marx, in setting out how labour is the source of value without, however, calling his own theory a 'labour theory of value' - is describing something new (in fact this problem has played a role even throughout the twentieth century). ${ }^{22}$ Such a focus completely misses the really innovative message of the text, namely that it is not labour but rather money that constitutes the dominant measure of value, the measure and the criterion for what is (not) produced.

Classical Political Economy posits that labour is the source of profit (Marx agrees with this, as do I, as is set out in Division 5). However, the defect of CPE is that it simultaneously takes 'labour' (in different varieties for different authors) to be the measure of value. In Reuten (1999a) I set out the similar confusion within some strands of current marxian economics. In Reuten (2005) I show how this confusion is also related to an inappropriate reading of the first three

21 In Capital Marx does not use the term 'Entzweiung' (literally 'splitting in two'). However, it is a term that Hegel (sparingly) used - see Benhabib 1986, p. 23 and Inwood 1992, p. 36 .

22 For Marx, labour is the source of value; however, he is far from proposing that 'labour is value' (which was Ricardo's view). 
chapters of Capital (where the term 'abstract labour' in the first two sections of chapter 1 is a placeholder for money, prior to the introduction of money).

1§5-d Addendum. Value-form theory: from value-form to monetary-value dimension

Since 1988 I have been a fierce proponent of 'value-form' theory. Nevertheless, to this point I have abstained from using the term 'value-form'. This is an issue of how to phrase the matter, rather than making any fundamental changes to the content. Value-form theorists, including myself, took on Marx's term of valueform (Capital I, Ch. 1) in their breaking away from value-theoretical 'labour embodied' interpretations of Marx's work (appraised in e.g. Reuten 1993 and 2004a) as well as from analogous currents within contemporary marxian theory (appraised in e.g. Reuten and Williams 1989; Reuten 1988 and 1995). This is clear for the theoretical experts. The expert knows that the term 'value-form' in one of its main focuses - is used to emphasise that 'value' is not a naturalistic concept, but rather one that is always specific to and 'determinate' (Murray 1988) for particular social formations (such as capitalism); furthermore, for capitalism value's main determinate form is monetary. However, the term 'valueform' by itself leaves the latter unspecified. In short, I have mainly substituted the term 'monetary-value dimension' for 'capitalist value-form', even if the connotations of the two terms are somewhat different.

\section{$1 \S 6$ Commodification of labour-capacity and commodified consumption}

As labour is required for production $(1 \S 1)$, it now becomes manifest that with the trade relation, the monetary-value dimension and the commodification presented so far $(1 \S 2-1 \S 5)$ - the existence of enterprises generally requires them to purchase the capacity to labour during production, in which sense they are employers of labour.

Correspondingly, to the extent that labourers lack means of production, their existence compels them to sell their labour-capacity, to be employed for part of the day (thus their existence is grounded in that sale). Depending on their skills, they are not forced to sell their labour-capacity to a particular enterprise; however, they are forced to sell it to some enterprise. Thus the dissociated outward bifurcation requires that labour-capacity is traded on a market.

Because in capitalism the capacity to labour is not traded in its entirety (as is the case in systems of slavery), but rather for a stipulated amount of time, its trade occurs in terms of hiring and renting out (i.e. time-constrained buying and selling).

As with the outputs of production and the other inputs to production, the capacity to labour is assessed at the market such that heterogeneous capacit- 
ies are made commensurate in terms of one-dimensional monetary value a dimension alien to the physical capacity to labour (cf. $1 \S 4)$. Thus we have a commodification of labour-capacity - it is traded on a market like a commodity. Similarly, it is through the money medium that the trans-abstraction of value concretely appears as reflected market transformation of labour-capacity (cf. $1 \S 5)$. Hence the latter appears in the inwardly bifurcated guise of 'capacity' and 'monetary value', which constitutes it as 'commodified' (cf. 1§5). More specifically, the commodified labour-capacity is bifurcated into 'capacity rented out for a certain amount of time' and 'rent in monetary value for a certain amount of time', the name for the latter being the 'wage for a certain amount of time' or, in short, the 'wage rate'.

Along with this commodification and the wage income deriving from it, the households' acquirement of production outputs of enterprises takes the form of commodified 'consumption'.

1§6-a Explication. The 'too common' market for labour-capacity Without the 'mirror' of other, different, societies it is notoriously difficult to analyse the most common aspects of one's own society. The market for labourcapacity (usually called the 'labour market') is a case in point. Our psychological need for concordance forbids us to even remotely compare the trading of labour-capacity with the trading of slaves. These are not the same; nevertheless, if we consider the matter in terms of selling and renting labour-capacity, this trading is something of a remnant of slavery trading. That is, with the qualification that labourers are free to choose an owner (of means of production) they are, generally, not free to not choose an owner. ${ }^{23}$ It may well be that the people of a few generations hence will look back on this in horror, just as we look back in horror at slavery.

1§6-b Explication. Contingency of 'self-employment'

The main text states: 'the existence of enterprises generally requires them to purchase the capacity to labour during production, in which sense they are employers of labour'. The term 'generally' implicitly refers to the contingency of small enterprises that do not hire any labour-capacity. Contingently a layer of self-employed labour is compatible with capitalism, which is conditioned

23 Again, as in the main text, this is predicated on the lack of means of production as including the capacity for borrowing these. (Hence the 'not being free' is a general statement; it does not rule out that some may be able to gather the means for being self-employed or to start up an enterprise; however the 'not being free' in this respect is a systemic statement; a society in which everyone were self-employed is definitely not capitalist.) 
on these labourers having ownership of their means of production. As indicated in $1 \S 1-\mathrm{e}$, in this book I refrain from characterising the type of economy we would have if this were no longer a mere compatible contingency, and instead pure self-employment had become generalised.

1§6-c Explication. 'Labour-capacity' versus 'labour'

I follow the marxian tradition which - contrary to mainstream economics makes a strict distinction between the concepts of 'labour-capacity' and 'labour'. It is the labour-capacity, or labour potential, that is traded at the market. In contradistinction, the activity of 'labour' (some manifestation of the capacity) ensues in production at some pace and intensity (expanded on in $1 \S 14$ and $2 \S 2$ ). Note that Marx considered the distinction as one of his main conceptual advances. The reason is that it articulates his particular exposition of the interconnection of the capitalist production process and the labour market, which is vital to his main work Capital.

1§6-d Addendum. The terms 'labour-capacity' and 'labour power'

Within the marxian tradition the common term for 'capacity to labour' is 'labour power'. The latter is a translation of the German 'Arbeitskraft' that Marx uses in his mature work. Capacity to labour is rather equivalent to 'Arbeitsvermögen', the term that Marx adopts in his early work and his drafts for Capital (until about 1865). One reason for adopting the term 'capacity to labour' is that, in my view, the term more appropriately covers the concept (i.e. of potential activity). Another reason is that I will introduce later on $(1 \S 14)$ the term 'productive power of labour' (a refinement of labour productivity) and I would not want to have this term confused with 'labour power'.

\section{$1 \S 7 \quad$ Inward bifurcation of commodities: the commodification of inputs and outputs 'in total'}

The capitalist commodity-form of entities - resulting from their reflected market transformation through the money medium - reveals the commodities' duality in their inward bifurcation into 'use-value' (usability) and 'monetary value'. With the exposition so far (esp. $1 \S 5^{-1 \S 6)}$ the near total commodification of the inputs and outputs of enterprises has been presented. I say 'near' because free nature $(1 \S 1)$ does not take on the form of monetary value, and hence does not appear as input costs for enterprises. (Later on it will be made explicit that this can be seen as a curse rather than a blessing.)

Herewith, the exposition has reached the point where elements for a potential solution to the 'dissociated outward bifurcation' appear $(1 \S 1)$. However, whereas the dualities posited may seem surmountable (if not straightforwardly 
so) for households, dual measures deliver no determinate criterion for the production within enterprises - so far the trade of specific inputs and outputs. Hence the exposition must be expanded ( $1 \mathrm{D}_{4}$ below).

\section{Division 4. Profit - duality dominated by the monetary-value dimension}

\section{$1 \S 8 \quad$ Profit as the monistic driving force of enterprises}

The dissociated outward bifurcation entails that the physical product of enterprises is generally not destined for its producers; hence the driving force of enterprises must be an aim external to its physical product $(1 \S 3)$. With market trade, both the inputs and outputs of enterprises are constituted as dual entities: inwardly bifurcated commodities that are qualitatively homogeneous in terms of monetary value $(1 \S 4,1 \S 7)$.

The non-physical external driving force of enterprises engenders monetary value as the dominant moment of the duality. Hence the external driving force of enterprises is a positive quantitative difference between the monetary value of the commodity inputs and the commodity outputs. This difference is called profit, which is - within the duality - the dominating monistic driving force of enterprises.

Whereas incidental profit can be explained on the basis of market trade (selling a commodity at a higher price than that for which it was bought), general, or macroeconomic, profit cannot be explained on the basis of the trade of goods in the form of commodities, since trade-gains would be cancelled out by trade-losses.

Thus, although we can comprehend the significance of the drive for profit, profit itself cannot be explained at the level of the moment of market trade $\left(1 \mathrm{D}_{2}-1 \mathrm{D}_{3}\right)$. Hence the exposition is still enmeshed in an 'impediment' to the continuity of the capitalist economy (cf. $\left.1 \mathrm{D}_{1}\right)$, whence it must expand to a new moment, which is production ( $1 \mathrm{D}_{5}$ below).

1§8-a Explication. Dominance of one-dimensional profit

So far the exposition has moved from outward institutional duality (outward bifurcation) to inward duality (commodification of entities). Each of the dualities is engrained in everyday capitalist life (as to the second: 'beautiful furniture you have, must be expensive'). Even if one-dimensional monetary profit drives enterprises, this is the dominant pole of the commodification. Dominance implies that the moment that is dominated (usability and physical and mental capacities) remains a moment albeit one shaped by the dominant moment. 
1§8-b Explication. Profit, trade and general equilibrium theory

The argument that within a (national) economy, trade surpluses and deficits cancel each other out - and hence that a macroeconomic surplus (i.e. macroeconomic profit) cannot be explained by pure trade $(1 \S 8)$ - is analogous to the cancelling out of international trade surpluses and deficits.

In neoclassical General Equilibrium Theory, 'net profits' (profits after interest payment) reduce to zero due to competition. This seems to absolve that theory from the explanation of the net profits (see also Naples and Aslanbeigui 1996). However, it does not relieve the theory of the task of explaining 'gross profits' (profits before interest payment). This fails to set out if and how general equilibrium, or anything even close to it, could be a feasible capitalist constellation, because zero profits, in each of these definitions, would presumably paralyse investment. (It is quite another issue that apart from periods of severe recession, macroeconomic profits are robustly positive.)

\section{Division 5. The capitalist production process Labour's productive power and the appropriation of surplus-value}

In this division the exposition moves from the market and the commodification of the inputs and outputs of production $\left(\mathrm{ID}_{2}-\mathrm{D}_{4}\right)$, to the production process of the outputs of enterprises - part of these serving again as inputs for other production processes.

Subdivision 5 A. The general form of the capitalist production process: duality of the production process and dominance of the monetary valorisation process

\section{$1 \S 9 \quad$ The production process as technical process}

In the exposition of abstract sociation, I used the phrase the creation of entities (1§o), which, with the outward bifurcation concomitant on dissociation, was particularised as production (1§1). Along with this, the activity of creation of entities ( $1 \S 0)$ was particularised as labour $(1 \S 1)$.

Like the activity of creation, the capitalist production process in its technical aspect is in essence a metabolism of human beings - more particularly 'labour' - with nature. The 'gift' of freely available nature is worked up by labour into means of production as products, and these together are worked up by labour into final products to be consumed.

With privately owned enterprises, means of production are privately owned $(1 \S 1)$. Then we may distinguish between the (still) freely available nature, such as sunshine, and appropriated nature, such as the majority of land. Appropri- 
ated nature is subsumed under the category of 'means of production' because it is traded like commodities, and functions like commodified means of production. Thus physical production entails some combination of:

- Freely available nature worked up by labour $\rightarrow \stackrel{\bullet \text { Means of Production or }}{\cdot \text { Final Product }}$

- Freely av. nature and means of production

$$
\text { worked up by labour } \rightarrow \stackrel{\bullet}{\bullet} \text {. Feans of Production or }
$$

The working up by labour of nature, or of nature and means of production, is called the physical production process, or the technical production process A technique of production refers to a qualitatively and quantitatively specific combination of nature, means of production and labour alongside a qualitatively specific labour process.

\section{$1 \S 10$ The production process as monetary valorisation process: 'ideal pre- commensuration' and the inward bifurcation of the production process}

Through the money medium in the market, the trans-abstraction of value concretely appears as the reflected transformation of entities into dual commodities $(1 \S 7)$.

Because trade in the market is not accidental but systematic, the abstraction of the equation of a product to some definite amount of money can be anticipated prior to market trade. Before the actual market trade, stocks ideally represent an amount of monetary value. The same applies for the commodities that are in the process of production, i.e. for the inputs that are being worked up by labour. Thus the actual commensuration in the market $(1 \S 5)$ is anticipated by an ideal pre-commensuration, and the transformation in the market is anticipated by an ideal transformation.

Or, to put it in slightly different terms: Only by way of the actual trade in the market do commodities show their actual value in terms of money (in that split second, so to speak). At all other times, commodities and commodities in process of production merely have an expected, or anticipated, value (i.e. value in the minds of the owners of the enterprises and the management), that is, 'ideal value. $^{24}$

24 Here and in the following section, 'management' is referred to in passing. It will be systematically introduced in Chapter 2. At the current stage of the exposition, the owners of enterprises can also be considered as the management. 
Hence the multifaceted physical technical labour process is inwardly bifurcated into the technical labour process and the one-dimensional ideal monetaryvalue-producing process, or, in short, the ideal valorisation process, the production of ideal value.

Given the value of the material inputs (means of production), this ideal valorisation process thus regards the production of new, additional value, commonly called 'value-added' (expanded in $1 \S 12$ ).

(Generally, 'valorisation' is the production of monetary value; its production is actually validated when the output is sold on the market - 'validation' being the turning of the output into money. ${ }^{25}$ Having made explicit, first, that valorisation always refers to monetary valorisation, and second, that during production valorisation is always 'ideal' valorisation, the remainder of this chapter uses the shorthand 'valorisation' or 'valorisation process', unless the adjectives monetary and/or ideal require emphasis.)

$1 \S 10-a \quad$ Addendum. Ideal pre-commensuration

The concept of ideal pre-commensuration of production was first outlined in Reuten (1988, pp. 53-5) and Reuten and Williams (1989, pp. 66-8). This concept is of great importance for the appraisal of the capitalist production processes, because it is denied that the latter are pure technical processes of 'neutral progress. ${ }^{26}$ A notion of putative neutrality applies to all of mainstream economics. Viewing ideal pre-commensuration in terms of inward bifurcation - one of the major themes of the present book - makes this even more explicit.

Positively, pre-commensuration is key to the intervention in one variety of marxian theory, i.e. one that casts the production process in physical 'labour embodied' or similar terms (see Reuten 1993). Pre-commensuration clears the way for the analysis and synthesis of production in terms of monetary value.

25 Addendum 1§12-b offers a brief comparison of Marx's and my delineations of the term 'valorisation'.

26 When Arthur (2001, p. 22) uses the term ideal pre-commensuration, he focuses on an aspect that is alien to my meaning of the term. He writes: 'Of course it is convenient for capital if the concrete forms of labour are simple enough to make an ideal 'precommensuration' of the labour time determining the value it hopes to realise on the market'. This is not the point of $1 \S 10$ above, where the pre-commensuration is in terms of the monetary value realised on the market; the (non-)complexity of the physical production does not affect this. 


\section{$1 \S 11$ Dominance of the monetary valorisation process over the technical} process: the inwarded drive for profit

The production process as yet being bracketed (abstracted from), profit has so far been posited as the (within the commodity duality, dominant) monistic external driving force of enterprises, aiming at a positive quantitative difference between the monetary value of the commodity inputs and the commodity outputs $(1 \S 8)$.

With the inward bifurcation of the production process into technical labour process and valorisation process $(1 \S 10)$, the external driving force of profit $(1 \S 8)$ is homogeneously connected to the process of production. More precisely, the connection lies in the production process being dominated by one of its two bifurcated poles, that is, the valorisation process. ${ }^{27}$ Thus through the monistic driving force, the dual production process is dominated by the production of ideal monetary value. Herewith the profit as external driving force $(1 \S 8)$ is ideally inwarded within the enterprise as unit of production. In other words, the external profit drive in terms of inputs and outputs $(1 \S 8)$ transforms into an inwarded driving force of production: the production of ideal profit. . $^{28}$

The inwarded drive for profit, a surplus of one-dimensional monetary value, is essential to the capitalist system. However much the market trans-abstraction $(1 \mathrm{D} 2,1 \S 4)$ and the market transformation and inward bifurcation of the commodity $\left(\mathrm{1D}_{3}\right)$ are constituent for the inward bifurcation of capitalist production $(1 \S 10)$, it is the latter bifurcation together with the inwarded drive for profit that is pivotal to the capitalist system. The trans-abstraction in the market reflects on ready entities. However, the inward bifurcation of production, together with the inwarded drive, is much more far-reaching, to the extent that valorisation-driven production affects the human creation of entities, that is, their material make-up, their material constitution; in this way the technical labour process $(1 \S 9)$ is instrumental to the valorisation process.

Thus it is not the case that merely a 'pre-given', neutral, technical labour process is denominated in terms of ideal monetary value; rather the technical process is devised and managed as a valorisation process and so affects the technical process. Thus with the inwarded driving force, the commodity that was presented in $1 \mathrm{D}_{3}$ is 'not innocent', so to speak. Rather, the output of enterprises that was presented as actually trans-abstracted and transformed on the market

27 Valorisation is the generation of monetary value (cf. $1 \S 10)$.

28 It is ideal because prior to the actual sale of commodities, we have no more than an expected value as including an expected profit (cf. $1 \S 10)$. 
(the value leap referred to in $1 \S 4$ ) - as indeed it is - is preceded by the capitalist profit-driven production as production of commodities, that is, production of ideal commodities ('ideal' before the actual leap).

Hence the necessary requirement for the production of multifaceted entities $(1 \S 0)$ is overarched by the driving force of production for one-dimensional monetary value: profit. Therefore, first, that which can be perceived - in production plants or on retail shelves - is pre-selected on the basis of the profit criterion; entities that cannot be produced profitably are simply not on offer. Second, the quality of the entities (in terms of nutrition, health, durability, environmental symbiosis) is subordinate to the quantity of one-dimensional profit.

1§11-a Explication. Potential threat of inward bifurcation of production The main section just presented is one core of this chapter. In brief: the combination of the inward bifurcation of the commodity with the pre-commensuration means that the (now 'merely') external profit drive, in terms of inputs and outputs, transforms into an inwarded production drive, whereby production itself is affected by the monetary-value dimension.

This poses a potential threat to a continuous social whole (the subordination of quality in terms of nutrition, health, durability and environmental symbiosis referred to). Because it is 'merely' a potential threat, I methodologically absolve myself from providing a solution to it at the current level of the exposition. What is more, the (potential) problem cannot be resolved at the level of the capitalist economy pure (i.e. Part One of this book). I will return to this issue when the exposition can deal with it, that is, when the state has been introduced in Part Two (see Chapter 6).

1§11-b Explication. Linear exposition along with reinforcing simultaneity of moments

The exposition in the text of a book is inevitably linear (see the middle column of Scheme 1.3). In fact we have a reinforcing simultaneity of the moments as in a circuit (the dotted lines in that scheme). Similar schemes can be made for other parts of the exposition. 
SCHEME 1.3 Linear exposition along with reinforcing simultaneity of moments: $1 D_{3-1} D_{5} A(1 \S 5-1 \S 11)$

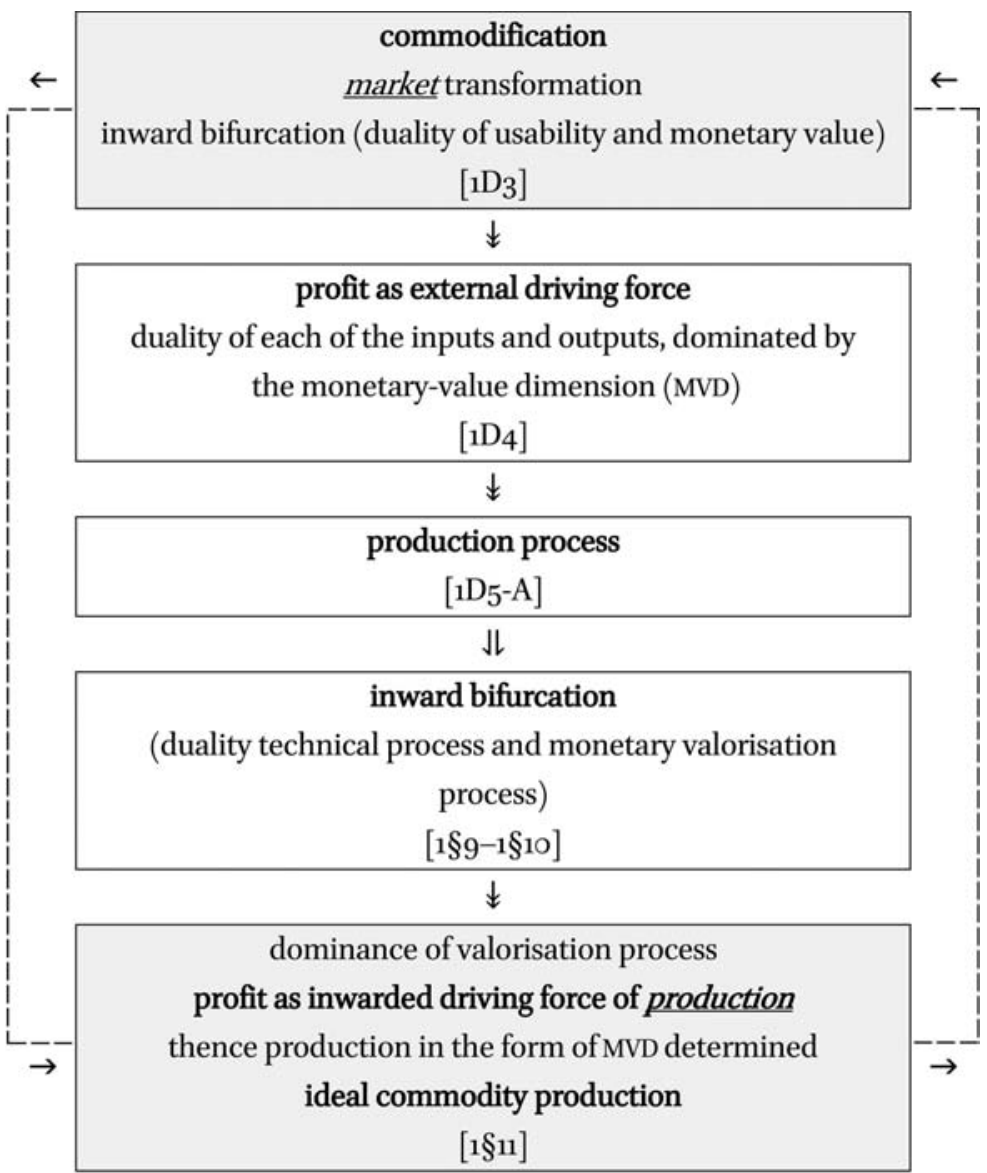

Legend

$\Downarrow \quad$ grounded in (conditioned by)

Ut implicit herein

$\leftrightarrow \quad$ reinforcing simultaneity

Subdivision ${ }_{5}$ B. Measures and determinations: surplus-value, capital as timegrasping investment, and the production of capital

$1 \S 12$ The articulation of value-added and surplus-value (integral profit) The result of the enterprises' valorisation $(1 \S 10)$ is the value-added in enterprises, which is the sum of all the income categories generated in enterprises. In brief, these income categories are the sum of wages and surplusvalue. 
So far the term 'profit' (1§8) has yet to be delineated - it was used in a rather general everyday sense of the term. This is a matter of exposition, simply because all the relevant interconnected concepts cannot be introduced at the same time. The term 'surplus-value' is the genus term for the two sub-categories of profit (retained and distributed) and interest. The latter applies to the extent that enterprises use external finance. This sub-division of surplus-value is systematically introduced in Chapters $2-3$.

Next to wages the remainder of the current chapter focuses on the production of surplus-value because surplus-value is independent of the contingent ways in which particular enterprises finance the production.

Throughout this book the term surplus-value will be used interchangeably with the term 'integral profit' (with exactly the same meaning). The reason is simply that I need the concept of the 'rate of integral profit' (introduced in the next section), whereas for theory-historical reasons the term 'rate of surplusvalue' would be confusing. ${ }^{29}$

Returning to the first sentence above, the result of the enterprises' valorisation is the value-added in enterprises. The latter is the starting point for what follows in this division. Thus we have:

Surplus-value $\triangleleft=$ Value-added - wages

(where the sign $\varangle$ denotes right to left hand determination). ${ }^{30}$

In this chapter the level of the wages is pre-posited (presented in Chapter 2). Hence given the wages level, the level of the surplus-value is determined by the value-added, that is, the valorisation. Thus, for now, the main question is the explanation of value-added (presented in $1 \S 14$ ), which we arrive at after the introduction of the concept of capital (1§13).

1§12-a Amplification. The concept of surplus-value and the SNA concept of 'operating surplus'

The current System of National Accounts 2008 (UN 2009) adopts the macroeconomic surplus concept of 'operating surplus'. The SNA starting point is output minus intermediates (purchases and sales between enterprises) and minus wages. That starting point for the operating surplus (OS) would be equival-

29 I would have preferred to evade the term integral profit. However, the term 'rate of surplusvalue' has ineradicably been coined by Marx as a measure for the capital-labour distribution of income (more precisely, the rate of exploitation).

30 In common macroeconomic terms (SNA) the domestic value-added is defined as $\mathrm{Y}=$ operating surplus + wages. See $1 \S 12$-a on the distinction between operating surplus and surplus-value. Definition $(=)$ is not the same as order of determination, for which I adopt the sign $\varangle=$. 
ent to our concept of surplus-value. However, the SNA also adopts a number of arbitrary imputations, which cause the two concepts to deviate (expanded in $8 \S 6-d)$.

1§12-b Addendum. The term 'valorisation' in comparison with Marx's use of the term

In $1 \S 10$ I introduced the term 'valorisation'. Now that the term 'surplus-value' has been introduced (1§12), I can properly comment on my usage of the term 'valorisation'. In Das Kapital I, Marx makes a distinction between the Wertbildungsproze $\beta$ (which refers to the production/creation/generation of value) and the Verwertungsprozeß (which refers to the production/creation/generation of surplus-value). For the latter Marx also uses the term Bildung von Mehrwert. ${ }^{31}$ The term Verwertung is now commonly translated by 'valorisation' (following Fowkes; see the previous footnote).

For the purposes of the current chapter I use the single term 'valorisation' for value creation (that is, the production of 'value-added'), making clear when I specifically refer to surplus-value. My main reason for this usage is methodological: in capitalism the production of surplus-value is a necessary moment; capitalist value-production is generally value-production as including the production of surplus-value (only contingently may this not be the case). ${ }^{32}$ From this point of view, Marx's two terms coincide (or rather the one is sublated into the other).

\section{$1 \$ 13$ Capital and time - the rate of integral profit and standard time}

Both the inputs and outputs of enterprises are constituted as dual entities: inwardly bifurcated commodities that are qualitatively homogeneous in terms of monetary value $(1 \S 4,1 \S 7)$. The enterprises' driving force of profit, aiming at a positive quantitative difference between the monetary value of the commodity inputs and the commodity outputs $(1 \S 8)$, is constituted as an inwarded production of ideal profit (1§11) further specified as integral profit, or surplus-value (1§12).

31 Marx's German terms are somewhat idiosyncratic and for each of these terms there is no simple English translation. Here are some page references. Marx, Das Kapital I (1962 [1867'; $\left.\left.189 \mathrm{o}^{4}\right]\right)$, p. 171 and p. 209; Fowkes translations: Marx, Capital I $\left(1976\left[1867^{1} ; 1890^{4}\right]\right)$, p. 259 and p. 302.

32 Marx in fact introduces the capitalist necessity of surplus-value via its contingent negation. 
On the basis of divisions $\mathrm{1D}_{2}-\mathrm{1}_{5} \mathrm{~A}$ we can now identify the enterprises' inputs to production under their common empirical names of 'investment' and 'capital'. One aspect of active 'capital' is the monetary value of the enterprises' investment in physical inputs for production - inputs that themselves are constituted as dimensionally dual inputs. However, the developed concept of capital also incorporates 'time', that is, the duration of the production process and so the duration of investments. Thus capitalist production entails not 'merely' its grasping of 'usability' under the dominating monetary value-form; it also entails its grasping of time under 'production time'. Efficient process management in terms of valorisation (as quantity of value) is twinned with efficient process management in terms of production time, as distinct from any other time. (When a feudal farmer, after much hard work, takes the corn harvest to the miller during a quiet three-hour horse and carriage ride, this activity is not obviously perceived as work rather than rest.) In the economics discourse 'efficiency' is often something of a catch-all term. Unless otherwise stated I use the term to mean 'profit-geared efficiency'.

Contingent time span of physical-technical production processes

Given this production process efficiency in its twinned aspects (quantity of monetary value and duration), production is nevertheless chained to the moment of a physical-technical production process and its duration. In particular, surplus-value is gained on the investment of inputs for the specific technical length of time of various particular 'singular production processes' (of wheat, computers, pens, etc., taking a number of months, weeks or less than an hour, as the case may be). That is, surplus-value seems chained to the contingent pace of physical-technical production, even if this is subsumed under valorisation. In principle this 'singular-process-integral-profit' (spp) can be calculated per the amount of 'singular-process-inputs' (spi) at some rate - that is, (spp)/(spi). ${ }^{33}$ However, the different duration of the singular processes in different branches of production (or perhaps also within the same branch) means that (spp)/(spi) is insufficient as a measure for the comparison of achievements between enterprises. Thus this measure provides no criterion for what physical commodities are most profitable to produce.

33 This is how Marx initiates his exposition of the production of surplus-value in Capital I, getting to turnover times of capital in the second part of Capital II. What I present in the next subsection (3) is what Marx, qua field of exposition, presents in the second part of Capital III. 
The total 'active capital' $(K)$ consists of, first, the enterprise's investment in inputs for production and, second, the running valorisation - the latter being co-materialised in the ideal monetary value of half products and not yet validated output stocks. This capital can, in principle, be measured at each point in time, as reported on an enterprise's balance sheet (see explication $1 \S 13-a)$. The latter is captured in the notion of 'active capital' adopted henceforth, which, to be sure, is a sum of one-dimensional monetary value. So as to overcome the insufficiency alluded to under point 2 , the duration of capital investment instead of measuring it relative to the rhythm of physical production - is established relative to a conventional standard time: the calendar year (from now on indicated by subscript $\mathrm{t}$ ).

Then the standardised total integral profit $\left(\mathrm{pi}, \Pi_{\mathrm{t}}\right)$ is the summation over a year of the integral profits gained in each singular production process during the year.

Along with it, the integral-profit-driven production is purified in the measure of the integral-profit-rate of capital as unchained from the rhythm of physical production. This is the rate of the integral profit gained during the year, and measured at the end of the year, over the capital invested at the beginning of the year (omega, $\omega)$ :

$$
\omega_{\mathrm{t}}=\Pi_{\mathrm{t}} / \mathrm{K}_{\mathrm{t}^{\prime}}
$$

(where the subscript $t$ indicates the end of year $t$, and $t^{\prime}$ indicates the beginning of year $\mathrm{t}$ ). Note that $\Pi_{\mathrm{t}}$ is a flow and $\mathrm{K}_{\mathrm{t}^{\prime}}$ a stock.

Thus capital and the production of integral profit (i.e. surplus-value) is constituted as unity of investment, valorisation and standard time. The rate of integral profit per standard time $\left(\omega_{t}\right)$ is the purified criterion for what, and how, physical commodities are most profitably produced. Ultimately each of the particular commodity that is produced, and how it is produced, is merely instrumental for the generation of the thus measured optimal rate of integral profit.

1§13-a Explication. Active capital: simplified balance sheet of enterprises Whereas capital has the monetary-value dimension, it is not money. Most of the time, i.e. during production, it exists in a state of ideal value (cf. 1§10). This is revealed on the enterprises' balance sheet (Figure 1.4), which in fact expresses the 'state' of capital at the point in time of the report. ${ }^{34}$

34 This value ideality of capital poses a major problem for enterprises, statistical bureaus, the science of economics, and the business press. The values stated are book values. This 
FIGURE 1.4 Simplified balance sheet of an enterprise (per some specific date)

\begin{tabular}{|c|c|c|c|}
\hline \multicolumn{2}{|l|}{ Assets (active side) } & \multicolumn{2}{|l|}{ Liabilities (passive side) } \\
\hline Plant and fixed equipment & .... & Capital ${ }^{\ddagger}$ & .... \\
\hline Raw materials and current equipment & & & \\
\hline ('floating' means of production) & $\ldots$. & & \\
\hline Production in process & $\ldots$. & & \\
\hline Ready product & $\ldots$. & & \\
\hline Bank account $(+/-)^{\dagger}$ & $\ldots$ & & \\
\hline Total active capital & $\mathrm{K}$ & Total passive capital & $\mathrm{K}$ \\
\hline
\end{tabular}

$\dagger \quad$ Introduced in Chapter 2. (In fact this entry is no active capital; generally it cancels out when bank loans are taken into account, also introduced in that chapter).

$\ddagger \quad$ This entry abstracts from the way of finance - introduced in Chapter 3. (Provisionally the entry may be conceived of as one in which all finance is internal finance, as might contingently be the case).

1§13-b Explication. Equalities and equality signs in this book

An equality is always an equality in terms of a particular dimension and standard (this applies for any applied mathematics generally). Let euro $(€)$ be the monetary standard. Then the monetary-value dimension in terms of $€$ may be denoted as mv€. Precision requires that we always write, for example:

$$
\mathrm{M}={ }_{\mathrm{mv} €} \mathrm{C}
$$

i.e. $\mathrm{M}$ is equal to $\mathrm{C}$ 'in the monetary-value dimension with the standard measure of $€$ ' (see Ellis 1968, p. 25). Henceforth in this book, and unless otherwise indicated, the symbols of $>$ of $=$ and of < always mean, respectively, 'greater in mv€', 'equal in mv€', and 'less in mv€' (or any other monetary standard).

\section{$1 \S 14$ Appropriation of the productive power of labour}

The generalised explanation of (integral) profit requires the movement from the market to production (1§8). Regarding production as a physicaltechnical process, labour works up freely available nature as well appropriated means of production - the latter including appropriated nature (1§9). The next sections show how production itself takes on the monet-

issue will be a major theme throughout Part One of this book, and especially in Chapter 3 . This will also be crucial in further, more concrete, determinations of the relation between Finance Capital and Production Capital (Ch. 3) and of economic crises (Ch. 5). 
ary value-form and how the technical process is dominated by the valorisation process and the profit drive (1§10-1§11), 'the rate of integral profit over capital invested' being the quantitative criterion for the achievement $(1 \S 13)$.

On this basis I now return to the question of the explanation of valorisation, that is, the explanation of value-added and the surplus-value accruing to enterprises $(1 \S 12)$. In short, this section provides the grounding of the existence of value-added and of surplus-value. I note that until subsection 7 , the equations in this section are microeconomic (referring to an average enterprise).

\section{1}

\section{Costs of production and output}

Production is the transformation of inputs into outputs. The capitalist production process is accounted in terms of monetary value quantities and quantities of labour. I consider first the following main input and output quantities and quantitative relations. (Note that this subsection is somewhat tedious on account of the introduction of a number of new symbols).

- $\mathrm{L}_{\mathrm{t}}$ denotes the average number of workers employed during the year (in terms of the going full-time equivalent). The labour process, and hence $L_{t}$, is considered as a whole and includes the work around purchases and sales.

- $\mathrm{L}_{\mathrm{t}}$ is hired against a wage rate $\mathrm{w}$. Hence $\mathrm{wL}_{\mathrm{t}}$ is the wages sum.

- $\mathrm{K}_{\mathrm{t}}$ denotes the yearly average amount of capital in terms of monetary value, measured as the assets of the enterprise's balance sheet (see $1 \S 13-a$, Figure 1.4). The assets include the fixed means of production, the floating means of production (as including input stocks - raw materials) and output stocks. ${ }^{35}$ In this chapter I pre-posit the existing amount of capital as previously accumulated and invested in production. (This pre-position will be grounded in ${ }_{3} \mathrm{D}_{4}$.) $\mathrm{K}_{\mathrm{t}}$ is the amount of capital that can, on average, be operated by labour at each point of labour-time during the year.

- $\delta \mathrm{K}_{\mathrm{t}}$ is the value of the fixed assets used up during the year. These are expressed as a fraction $(\delta$, e.g. 1/5) of the total assets K. Fixed assets are those that last for more than one year. (Usually these used up assets are also replaced during the year. $)^{36}$

- $\mu \mathrm{K}_{\mathrm{t}}$ denotes the value of the floating means of production used up during a year. These are expressed as a coefficient $(\mu)$ of the total assets K. Floating means of production last less than one year, and these are purchased during

35 In the literature, the floating means of production (including input stocks) and the output stocks are also called 'working assets' or 'current assets'.

36 Replacement, non-replacement and depreciation are expanded on in Chapters 4 and 5 . 
the year. However, a part of these also appears on the balance sheet as stocks (used and replaced) as a continuous investment. (Therefore, and unlike $\delta, \mu$ is usually not a fraction of K. However, $\mu$ is like $\delta$ a 'technical coefficient', their sizes being determined by the technique adopted.) Macroeconomically $\mu \mathrm{K}$ is also denoted as the 'intermediate inputs. ${ }^{37}$

- $\delta \mathrm{K}_{\mathrm{t}}$ and $\mu \mathrm{K}_{\mathrm{t}}$ are more precisely to be measured as coefficients of the beginning of the year total assets $\mathrm{K}_{\mathrm{t}^{*}}$. In what follows I neglect this, as it would make the notation of the equations below cumbersome.

- $\Pi_{\mathrm{t}}(\mathrm{pi})$ denotes the surplus-value produced during the year.

- $\mathrm{X}_{\mathrm{t}}$ denotes the year's output of production.

- Except the stock of $\mathrm{K}_{\mathrm{t}}\left(\right.$ or $\mathrm{K}_{\mathrm{t}^{\prime}}$ ) all these variables above (including $\delta \mathrm{K}_{\mathrm{t}}$ and $\mu \mathrm{K}_{\mathrm{t}}$ ) are flows.

Taking these together we have:

$\mathrm{X}_{\mathrm{t}} 4=[(\delta+\mu) \mathrm{K}+\mathrm{wL}+\Pi]_{\mathrm{t}}$

(Where the sign 4 denotes that the determination is from the right hand side to the left hand side.)

This (1.2) is a costs and revenue equation, after production has taken place. The question is how the surplus-value ( $\Pi$ ) emerges. Before we have this result (1.2), in the early mornings so to speak, there is the enterprise that has yet to open its gates, at value ' $\mathrm{K}$. At the gate of the enterprise we merely have the labour-capacity $\mathrm{L}$. When the gate opens, and the production process begins, this labour-capacity is exerted as actual labour, which I denote as $\mathrm{L}^{\alpha}$, as further explained below.

2

Means of production in the form of capital

Production considered purely technically is the working up of nature and means of production by labour $(1 \S 9)$. Although freely available nature contributes to production, it has no price; it is freely available to all enterprises and therefore does not enter production prices, hence it is neglected in capitalist practice: it has no monetary value. ${ }^{38}$ Considering nature, it is only appropriated nature that, commodity-like, is traded and so has a price. Because for enterprises the distinction between appropriated nature and produced means of production is immaterial, I subsume the former under the latter.

37 The latter is the term usually adopted in macroeconomic accounts (cf. UN 2009, SNA 2008).

38 Perhaps the policy of the state might somehow enforce enterprises to mimic a price for the use of non-appropriated nature. However, the state has not yet been introduced into the exposition (see Part Two). 
Means of production derive their value from the process of production in which they were produced. ${ }^{39}$ They provide no value-added; rather they represent previous value-added, namely from the valorisation processes in which they have been produced previously. ${ }^{40}$ At the current level of the exposition, the input prices of means of production are taken as given (amplified in $4 \mathrm{D}_{2}$ and $4 \mathrm{D}_{3}$ ).

Labour-capacity

In contradistinction to means of production, 'labour' is not produced in the past, as it is the activity of production itself. If anything, it is labour-capacity that is "produced" previously. But the key point is that whilst labour-capacity is grasped by the monetary-value dimension (the wage), it is not 'produced' within the capitalist sphere of production as a commodity. Rather, it is created within the sphere of households $(1 \S 1)$. The price of labour-capacity (i.e. the wage) does not represent previous value-added and it has nothing to do with the 'price of production' of labour-capacity. ${ }^{41}$ At the current level of the exposition, I take the wage, the price of labour-capacity, as given (its determinants are amplified in $2 \mathrm{D} 2$ ).

4

Production: exertion of labour

In terms of valorisation (the production of value) the main distinction between means of production $(\mathrm{K})$ and labour-capacity $(\mathrm{L})$ is that the former is inherently a static element in the production process in which it functions, whereas labour-capacity in operation, i.e. labour $\left(L^{\alpha}\right)$, is the active element. Means of production can merely be operated or not be operated. Within the agreed amount of labour-time, labour-capacity operates means of production, and so exerts labour at some productive power $(\alpha)$, including a component of the intensity of labour. At zero intensity (in effect a strike) there is no production of value. Hence only labour potentially generates value-added.

39 Quite another matter is that the property of, or the command over, any (temporarily) absolutely scarce element of production can always give rise to rent. I return to rent in Chapter 3 (Appendix 3c).

40 Nevertheless, it is the current ideal value of means of production (as related to the current cost price of similar means of production) that is in all or in part transmitted in the current production process (cf. $4 \S 7$ ).

41 Labour-capacity is created in the private sphere of the household; what is involved is the activity of procreation - it is not produced with a view to sale. It is created within the household sphere, and used (exerted labour) in enterprises; (final) commodities are produced within enterprises and used within households. The fact that skilled labourcapacity may have a higher price than the non-skilled is besides the main point that children are not produced for sale and hence do not have an actual price of production. 
Take the case of a (nowadays apparently fascinating) ready-made robot as means of production, and imagine that it requires hardly any operation by labour. That robot (as with any other means of production, as indicated under 2) derives its value from the process of production in which it was produced. Assuming for the sake of simplicity that the robot would require no current inputs at all, then the output value of the robot $\left(X^{R}\right)$ reduces to its purchase costs, whence there is no value-added. If the robot is not ready-made (and so requires adaptation within the current process of production), then the current operation by labour comes in again. ${ }^{42}$ (With some amendments about current costs, in respect of value there is no fundamental difference between robots and the early nineteenth-century use in production of horses - with apologies to the horses - and indeed between robots and any other means of production.)

Fascinating, generally, is not so much the actual use of ' $\mathrm{K}$ ' in current production, but rather the previous production of new means of production and hence the human creation of new technology and new technical applications of it which are creations by labour.

5

Production: components of the productive power of labour

I just mentioned the productive power of labour and the intensity of labour. I make a distinction between the actual labour as exerted at some techniqueassociated productive power $(\dot{\alpha})$, and the actual labour as exerted at some intensity of labour (i, iota). As such we have $\alpha=(\dot{\alpha})^{*}(i)$ and

$$
\mathrm{L}^{\alpha}=\mathrm{L}^{\alpha i ̈}
$$

Note that $\alpha, \dot{\alpha}$ and $\ddot{i}$ are exponents (not indices). Thus $\alpha$ is, qua content and mathematically, the power to which $\mathrm{L}$ is raised. ${ }^{44}$

Technique of production, the 'productive power of labour', the 'unit monetary value of labour' and the rate of integral profit

A technique of production refers to a qualitatively and quantitatively specific combination of nature, means of production and labour together with a qual-

42 The same applies if the sales and transport of the robot output are themselves not robotised - that would again involve a production process.

43 This concerns what Marx, in Capital , chapter 1, calls 'concrete labour' (1976 [18671, 189o4], p. 128).

44 Mathematically this implies decreasing returns to scale. The economic rationale is that given a technique of production and the associated $\alpha$ and $\dot{\alpha}$, there are increasingly limits to the potential intensity of labour: at some point the intensity of labour cannot be increased any further. 
itatively specific labour process, resulting in an output $(1 \S 9)$. For different commodities this physical output is no more than an intuitive notion because these cannot reasonably be added up $\left(\mathrm{1}_{2}-1 \mathrm{D}_{3}\right.$ and 1 §10).

At the start of the production process ' $\mathrm{K}$ ' is the value of the production plant and equipment when workers have just entered the premises' gates, without yet having worked. Even if the production process is dominated by monetary value and valorisation $(1 \S 11)$, it necessarily also remains a physical-technical process. In the actual production process, labour physically works up the plant and equipment to something qualitatively different (the physical output). This qualitative transformation is one aspect of labour's power. The other aspect is the quantitative valorising transformation. Alpha $(\alpha)$ is the 'parameter' of transformation: the productive power of labour in both these respects.

On the basis of the previous argument (points 2-5), equation 1.2 can now be concretised into:

$$
\mathrm{X}_{\mathrm{t}} \triangleleft=\left[(\delta+\mu) \mathrm{K}+\mathrm{mL}^{\alpha}\right]_{\mathrm{t}}
$$

where $\mathrm{mL}^{\alpha}$ has the dimension of homogeneous monetary value. ${ }^{45} \mathrm{I}$ call $\mathrm{mL}^{\alpha}$ the actual monetary value of labour, with ' $m$ ' being the actual unit monetary value of labour. (Practically ' $m$ ' measures the validation, the sale, of the net product of labour). ${ }^{46}$ Note that $\mathrm{mL}^{\alpha}$ includes the equivalent of the wages component $\mathrm{wL}$.

Thus given $\mathrm{K}$ and the implied (potential) technique of production, with the technical coefficients $\delta$ and $\mu$, the net value-added $\left(\mathrm{mL}^{\alpha}\right)$ is determined by the productive power of labour $(\alpha)$ as resulting in the actual monetary value produced by labour. So we have for 'surplus-value' or 'integral profit' (pi, $\Pi$ ):

$\Pi_{\mathrm{t}} 4=\mathrm{mL}_{\mathrm{t}}^{\alpha}-\mathrm{wL}_{\mathrm{t}}$

Whereas $\mathrm{K}$, the means of production that have been purchased, constrains possible production, the power of labour $(\alpha)$ determines how much output is actually produced. This is the big leap in a capitalist economy. The implication is that labour - more specifically, the actual productive power of labour - is the unique source of valorisation. Nevertheless this productive power is always based on the actual technique of production. Technology and its application in specific techniques is inevitably the result of social labour. (Choices of particular techniques are driven by competitive forces, amplified in Chapter 4.) Further, the productive power of labour usually diverges between sectors of

45 This is analogous to what Marx calls 'abstract labour' (in the same reference as in the one but last note).

46 If this is helpful for the reader: at this point ' $m$ ' can be considered as the realised price of the net product of labour. I return to this in more detail in Chapter $3(3 \S 10)$. 
production as well as within sectors of production, along with differing techniques of production. ${ }^{47}$

Finally on this point, using equations 1.1 and 1.5, we have for the rate of integral profit $(1 \S 13)$ :

$$
\omega_{\mathrm{t}}=\Pi_{\mathrm{t}} / \mathrm{K}_{\mathrm{t}^{\prime}}=\left[\left(\mathrm{mL}^{\alpha}\right)_{\mathrm{t}}-(\mathrm{wL})_{\mathrm{t}}\right] / \mathrm{K}_{\mathrm{t}^{\prime}}
$$

Thus given $\mathrm{K}, \mathrm{L}$ and the technique, the rate of integral profit $(\omega)$ varies with the wage rate $(w)$ and the productive power of labour $(\alpha)$.

Neglecting for now any distribution of surplus-value (and hence consumption out of surplus-value by capital owners - presented in Chapter 3), it follows from the exposition above that capitalist production, as dominated by valorisation, results in essence in a growth of capital (amplified in 2D1):

$$
\begin{aligned}
& \mathrm{K}_{\mathrm{t}^{\prime}}+\Pi_{\mathrm{t}} \Rightarrow \mathrm{K}_{\mathrm{t}} \text { or } \\
& \mathrm{K}_{\mathrm{t}^{\prime}}+\Delta \mathrm{K}_{\mathrm{t}^{\prime}} \Rightarrow \mathrm{K}_{\mathrm{t}}
\end{aligned}
$$

Because it is labour that produces the surplus-value $(\Pi)$ and hence any growth of capital, labour essentially produces capital - the owners of capital claiming the entitlement to its appropriation (amplified in 6D1).

\section{Measures of value-added}

We had, for what I now explicitly call gross production:

$$
\mathrm{X}_{\mathrm{t}} \triangleleft=[(\delta+\mu) \mathrm{K}+\mathrm{wL}+\Pi]_{\mathrm{t}}
$$

and next:

$$
\mathrm{X}_{\mathrm{t}} \triangleleft=\left[(\delta+\mu) \mathrm{K}+\mathrm{mL}^{\alpha}\right]_{\mathrm{t}}
$$

For gross value-added, $\mathrm{Y}^{\mathrm{G}}$ (macroeconomically, GDP) we have:48

$$
\mathrm{YG}_{\mathrm{t}} \triangleleft=\left[\delta \mathrm{K}+\mathrm{mL}^{\alpha}\right]_{\mathrm{t}}
$$

For net value-added (macroeconomically, NDP):

$$
\mathrm{Y}_{\mathrm{t}} \triangleleft=\left[\mathrm{mL}^{\alpha}\right]_{\mathrm{t}}
$$

47 Because $\alpha$ in $L^{\alpha}$ is a technique-associated power (in its component of $\dot{\alpha}$ ), $\alpha$ varies between sectors of production (expanded in $2 \S 2$ ). In Chapter $4(4 \S 4)$ we will see that $\alpha$ usually also differs within sectors of production, though within smaller margins.

48 In a macroeconomic account, all microeconomic enterprises are by convention taken to be integrated into one single enterprise. This implies (assuming a self-sufficient macroeconomic constellation) that the intermediate deliveries between enterprises cancel out. (One reason for this convention is that the thus measured 'output' is independent of the actual degree of enterprises' merging.) In terms of the equations above, this especially implies $\mu=\mathrm{o}$. (Note that for current economies $\mu \mathrm{K}$ often amounts to roughly the sum of the GDP - thus the sum of the microeconomic production being very roughly twice the sum of the macroeconomic production.) 
Note that the previous equations can be applied both macroeconomically and microeconomically (for individual enterprises or for sectors of production) - for the latter, as indicated, both $\alpha$ and $m$ may diverge within and between sectors of production.

1§14-a Explication. Market- and production-related concepts of labour A strict distinction has been made between 'labour-capacity' and 'labour' (see $1 \S 6,1 \S 6-\mathrm{c}, 1 \S 6$-d and $1 \S 14$ ). Table 1.5 summarises this in comparison with orthodox economics and marxian political economy (MPE).

TABLE 1.5 Summary of the distinction between market-and productionrelated concepts of labour

\begin{tabular}{|c|c|c|c|}
\hline & Orthodox economics & $\begin{array}{l}\text { Conventional } \\
\text { marxian PE }\end{array}$ & This chapter \\
\hline $\begin{array}{l}\text { - distinction market- and } \\
\text { production-related concepts } \\
\text { of labour }\end{array}$ & no & yes & yes \\
\hline - market concept of labour & labour (L) & labour-power $(\mathrm{L})$ & labour-capacity (L) \\
\hline • market value of labour(-...) & $\mathrm{wL}$ & $\mathrm{wL}$ & $\mathrm{wL}$ \\
\hline - production concept of labour & labour $(\mathrm{L})$ & labour $(\mathrm{L})$ & labour $\left(\mathrm{L}^{\alpha}\right)$ \\
\hline & (= market concept $)$ & $\begin{array}{l}=\text { labour-power } \\
\text { exerted as labour }\end{array}$ & $\begin{array}{l}=\text { labour-capacity exerted } \\
\text { as labour, at a certain } \\
\text { production power }(\alpha)\end{array}$ \\
\hline $\begin{array}{l}\text { - } \text { surplus } \\
\quad(\mathrm{VA}=\text { value-added }) \\
(\mathrm{SV}=\text { surplus-value })\end{array}$ & $\mathrm{OS}=\mathrm{VA}-\mathrm{wL}^{\dagger}$ & $\begin{array}{l}\mathrm{SV}=\mathrm{mL}-\mathrm{wL} \neq \\
(\mathrm{mL}=\text { value-added })\end{array}$ & $\begin{array}{l}\mathrm{SV}=\mathrm{mL}^{\alpha}-\mathrm{wL}^{\ddagger} \\
\left(\mathrm{mL}^{\alpha}=\text { value-added }\right)\end{array}$ \\
\hline
\end{tabular}

$\dagger \quad$ OS = operating surplus. It is explained by the so-called 'productivity of capital' or by 'waiting with consumption', sometimes in combination with managerial labour as a separate labour category. (See also Naples and Aslanbeigui 1996).

$\ddagger$ See also $1 \S 14$-c.

1§14-b Addendum. Smith, Marshall and Keynes on labour and profits To conceive of only labour as potentially creative of value-added $(1 \S 14)$ has nothing to do with the question of whether or not profits are necessary within the capitalist system. For Adam Smith (1776), for example, profits are necessary. At the same time he leaves no doubt that labour is the source of value-added and hence of profit:

'Thus, the labour of a manufacturer adds, generally, to the value of the materials which he works upon, that of his own maintenance, and of his master's profit. ... Though the manufacturer has his wages advanced to 
him by his master, he, in reality, costs him no expense, the value of those wages being generally restored, together with a profit, in the improved value of the subject upon which his labour is bestowed.

SмIтн $1776^{49}$

However, for Marshall - one of the founders of neoclassical economics - as well as many neoclassical economists after him, capital is asserted to be productive, though not on capital immanent grounds, but rather because without its (presumed) productivity there would be no 'justification' (!) for profit:

'It is not true that the spinning of yarn in a factory, after allowance has been made for the wear-and-tear of the machinery, is the product of the labour of the operatives. It is the product of their labour, together with that of the employer and subordinate managers, and of the capital employed; and that capital itself is the product of labour and waiting: and therefore the spinning is the product of labour of many kinds and of waiting. If we admit that it is the product of labour alone, and not of labour and waiting, we can no doubt be compelled by inexorable logic to admit that there is no justification for Interest, the reward of waiting; for the conclusion is implied in the premiss'.

MARSHALL 1972 [189o'] , p. 587; emphasis added

The point to be stressed is not so much the odd concept of waiting which is somehow physically productive, but that 'justification' should be the reason for providing the argument.

Here follow two excerpts from what Keynes (1936) has to say on the issue:

'It is much preferable to speak of capital as having a yield over the course of its life in excess of its original cost, than as being productive. For the only reason why an asset offers a prospect of yielding during its life services having an aggregate value greater than its initial supply price is because it is scarce; and it is kept scarce because of the competition of the rate of interest on money. If capital becomes less scarce, the excess yield will diminish, without its having become less productive - at least in the physical sense.

I sympathise, therefore, with the pre-classical doctrine [i.e. prior to Marshall c.s., i.e. what is now called classical political economy] that everything is produced by labour, aided by what used to be called art and is now called technique, by natural resources which are free or cost a rent according to their scarcity or abundance, and by the results of past labour, embodied in assets, which also command a price according to 
their scarcity or abundance. It is preferable to regard labour, including, of course, the personal services of the entrepreneur and his assistants, as the sole factor of production, operating in a given environment of technique, natural resources, capital equipment and effective demand'.

KEYNES 1936, pp. 213-14

'Interest to-day rewards no genuine sacrifice ... The owner of capital can obtain interest because capital is scarce. But ... there are no intrinsic reasons for the scarcity of capital'.

KEYNES 1936, p. 376

In Chapter 3 we will see why there is no intrinsic reason for a scarcity of capital.

1§14-c Addendum. Comparison of the main text with conventional marxian theory

I begin with a brief reference to Marx's Capital I, Chapter 1. If we could abstract from the duality of capitalist commodity production (in fact we cannot), $\mathrm{L}^{\alpha}$ could be viewed as a vector of 'concrete labour' in the process of producing heterogeneous goods (useful entities). Given the actual duality, Marx's concept of what he calls 'abstract labour' is commodity-value producing labour (one pole of the duality). ${ }^{50} \mathrm{My} \mathrm{mL} \mathrm{L}^{\alpha}$ is analogous to the latter, after Marx's introduction of money as the actual measure of value (Capital I, Chapter 3). I note three issues. First, the dimension of $\mathrm{mL}^{\alpha}$ is monetary. Second, after Marx has introduced the measure of money, his term 'abstract labour' disappears in Capital. Third, in Capital I, Parts One to Three, Marx considers averages (the average enterprise and average capital and labour); therefore here my $\alpha$ is not prominent (Marx considers here 'socially average' - also called 'socially necessary' - labour-time). ${ }^{51}$ See Reuten 2017 about Marx's dynamic exposition in this respect in Part Four and after.

I now compare the exposition in $1 \S 14$ with conventional marxian theory, focusing on three main issues.

(1) Labour as the unique source of valorisation ( $1 \$ 14$, heading 6$)$. I argued why labour is the unique source of valorisation. In conventional marxian theory, labour has also been put forward as the unique element of the process of value creation. However, this has most often been argued for on the basis of some 'labour-embodied' theory of value. The argument in $1 \S 14$ posits the uniqueness of labour without any recourse to labour-embodied. (Indeed, the argument that only labour potentially creates value-added should in no way be read to

$5^{\circ} \quad$ Marx $1976\left[1867^{1}, 189 \circ^{4}\right]$, p. 128.

$5^{1}$ Ibid., p. 129. 
imply that value-added is in some way proportional to labour-time as a labourembodied theory of value would have it. The key point is that $\alpha$ is a variable at both the microeconomic and the macroeconomic level; and that $\alpha$ usually diverges between and within sectors of production.) The uniqueness of labour as presented in $1 \S 14$ is no reason for calling that a 'labour theory of value'. Rather, I have presented a monetary theory of value $\left(1 \mathrm{D}_{2}\right)$. However, it is correct to characterise the exposition of $1 \S 14$ as a labour theory of surplus-value (integral profit) - further amplified in the next chapters. Note that within the framework of a 'labour-embodied theory of value' my term 'value of labour' belongs to the negative heuristic (in the sense of Lakatos 1970).

(2) The price of labour-capacity ( $1 \$ 14$, heading 3 ). The thesis that the price of the capacity to labour (i.e. the wage) has nothing to do with the 'price of production' of labour-capacity, and that these terms are indeed incompatible, appears very un-marxian. ${ }^{52}$ The determination of the wage is amplified in $2 \mathrm{D} 2$.

(3) The productive power of labour $\left(L^{\alpha}\right)$ and the 'unit monetary value of labour' $(m)$, in the context of net value-added (1\$14, heading 8). Recall the equation for net value-added:

$\mathrm{Y}_{\mathrm{t}} \triangleleft=\left[\mathrm{mL}^{\alpha}\right]_{\mathrm{t}}$

This is a development and re-conceptualisation of an equation presented in a path-breaking work by Aglietta (1979 [1976], pp. 43-4). He writes (in a different notation for $\mathrm{Y}$ and $\mathrm{L})$ :

$\mathrm{m}=\mathrm{Y} / \mathrm{L}$

calling $\mathrm{m}$ 'the monetary expression of the working hour'. He next emphasises that this equation is not a definition, but rather 'the monetary constraint' for the realisation of value (i.e. the sale of commodities). I agree with his view about $\mathrm{m}$, and will return to this in Chapter $3\left({ }_{3} \mathrm{D}_{5}\right)$. However, after Aglietta, equation 1.8A became fashionable among a strand in marxian political economy (e.g. via the works of Lipietz 1985 and Foley 1986), ${ }^{53}$ and ' $m$ ' came to be called the 'monetary expression of labour-time' (MELT), with the constraint aspect moving to the background, though maintaining equation (1.8A) in varying notations.

Here I merely stress the fundamental difference between these equations in the terms $L$ versus $L^{\alpha}$. This is not about a simple mathematical point of the difference between the two equations being that the second (i.e. MELT) has $\alpha=1$. Instead, all the MELT conceptualisations neglect the varying productive power of labour between sectors of production (and often there is a homogeneous

$5^{2}$ Marx at least seems to have had in mind something like a price of production of labourcapacity, as he conceives the wage related to the 'reproduction of labour-power' ('labourpower', i.e. in our terminology, the capacity to labour).

See also Foley 2005 . 
labour and a labour-embodied notion behind this - e.g. Moseley 2005, esp. p. 3). Thus this concerns not a simplification $(\alpha=1)$, but rather a non-distinction. ${ }^{54}$ Even further, as far as I know, this distinction has never been made within marxian political economy, or in mainstream economics. ${ }^{55}$

Anticipating Chapter 4 I mention that sector-wise relatively high K/L ratios are usually associated with relatively high productive powers of labour $(\alpha>1)$ and vice versa $(\alpha<1)$. In fact an expected rise in the productive power of labour is a condition for the introduction of $\mathrm{K} / \mathrm{L}$ rising techniques (addendum $4 \S 4-\mathrm{d}$ ).

1§14-d Addendum. Capitalist production of babies and labour-capacity speculative remarks

Aldous Huxley's story in Brave New World is nowadays less of a fiction than it was at the time of its writing (1932). It is technically possible to produce babies in a capitalist production process and also to raise these to fit labour-capacity. The question is whether and when this could be profitable (and legally permitted). If this would be the case, then a self-contained circuit would be constructed in which it costs (aggregated) less than one hour of labour to produce the capacity for one hour of labour. As a result, labour-capacity would become an intermediate output and input, and the value of labour would reduce to zero. Hence with such an annexation of the 'creation'/'production' of labourcapacity, the source of value-added would disappear. Along with it, capitalism would disappear (cf. Reuten and Williams 1989, p. 9o).

\section{Subdivision ${ }_{5}$ C. Grounding (sublation) of the dissociated outward bifurcation}

\section{$1 \S 15$ The capitalist mode of production as solution to the dissociative 'provision of the material elements for survival' by enterprises}

Given that a form of material 'production' (generally: transformative activity) is indispensable for the survival of any society, the capitalist outward bifurcation into households and privately owned enterprises

54 This has nothing to do with the MELT being applied either micro- or macroeconomically. Reconsider the following equation, now interpreted as macroeconomic (but for what follows, the microeconomic case is no different):

$\Pi_{\mathrm{t}} 4=\mathrm{mL}_{\mathrm{t}}^{\alpha}-\mathrm{wL}_{\mathrm{t}}$

For the sake of argument, assume $\mathrm{m}, \mathrm{L}$ and $\mathrm{w}$ to be constant, with $\alpha$ being normalised to $\alpha=1$ (which is implicitly the case for the MELT approach). In this case a rise in $\Pi$ (integral profit) could not be explained because an increasing intensity of labour (ï) or a techniqueassociated rise in the productive power of labour $(\dot{\alpha})$ escapes from view.

55 However, it is very interesting that Marx, in a neglected chapter of Capital I (in Part Four, chapter 10 of the German edition, chapter 12 in the English edition), first makes the dis- 
appears as dissociative and hence utmost problematical ( $\left.1 \mathrm{D}_{1}\right)$. The enterprises' dissociative production appears as resolved (sublated) in the grounds (conditions of existence) of the monetary-value dimension, commodification and the dominance of the enterprises' profit drive $\left(\mathrm{iD}_{2}-\right.$ 1D4).

However, the enterprises' profit - more precisely surplus-value $(1 \S 12)$ - must be produced. One main condition for the production of surplus-value is that the 'physical-technical labour process' is grasped as a 'valorisation process' and be dominated by the latter in face of the production of surplus-value (1§9$1 \S 11)$. Along with it, 'capital' is constituted as the monetary value-form of the enterprises' investment in the inwardly bifurcated inputs for production, and as twinned with the grasping of time under production time. Posited relative to standard time the 'rate of integral profit on capital' is the purified criterion for the successful production of surplus-value $(1 \S 13)$. The so far final condition (ground) for the production of surplus-value is the enterprises' absorption of the productive power of labour as taking on the form of valorisation - the production of the value-added. Given the wages, labour so produces the surplusvalue and hence essentially produces capital (1§14).

Herewith the enterprises' dissociative production appears as resolved (sublated) in labour's production of surplus-value, which, along with the enterprises appropriating the surplus-value, satisfies the enterprises' driving force.

Although some major problems for the reproduction of the capitalist bifurcated economy now seem resolved, we will see in the following chapters that the resolution reached so far requires further conditions to be met.

1§15-a Addendum. General comparison of Chapter 1 with Marx's Capital In terms of the systematic of Marx's Capital, this chapter covers the fields of, roughly, Parts One and Two of each of the three volumes of Capital (together about 675 pages). ${ }^{56}$ Thus although we have in each case a movement from the abstract-general to the concrete-specific, the order is nevertheless different. Theoretically this chapter adopts a value-form approach emphasising the 'monetary-value dimension' taken on by entities within the capitalist system. Next to a particular bifurcation dialectic, the chapter presents theoretical progress on six issues.

tinction, but later (in Part Five of the book) provides an averages account in which the distinction is levelled out (discussed in Reuten 2017 and 2018).

56 Volume I, Chapters 1-6 (Chapters 1-4 in the German edition); Volume II, Chapters 1-17; Volume III, Chapters 1-12. 
(1) A development of the 'monetary value-form' theoretic approach for all of the fields mentioned (building on my earlier work when I used the brief term 'value-form' with the same meaning - cf. $1 \S 5-\mathrm{d}$ ).

(2) A refinement of the interconnection of value and money ( $\left.1 \mathrm{D}_{2}\right)$.

(3) The concept of ideal pre-commensuration and its effect on production $(1 \S 10)$ - building on my earlier work.

(4) A re-conceptualisation of 'capital' as ideal monetary value, constituted relative to standard time, from the first introduction of 'capital' onwards $(1 \S 13)$. (This conceptualisation is only remotely connected to Marx's and marxian ideas of the circuit of a 'singular process' capital (1§13, point 2) which does not imply that the latter can be dispensed with in other contexts).

(5) A particular exposition of labour as the unique source of surplus-value, in connection with the 'productive power of labour' (1§14).

(6) Points (1), (4) and (5) together imply that there is no general rate of profit related 'transformation problem', because my point of departure is 'full capital' rather than Marx's 'singular process' capital (which, in my view, is an embryonic conception of capital). ${ }^{57}$ In his exposition Marx postpones the concept of the rate of profit until Capital III, Part One. In my view, because the rate of integral profit $\left(\omega_{\mathrm{t}}\right)$ is essential at an abstract-general level (one that abstractly captures the totality of the capitalist economy), it must be presented early on.

These are also major interventions in much current marxian theory. (In order to keep this book within a reasonable length, I have refrained from extensive references to the current literature. Whilst it is straightforward enough to insert brief critical references when needed, it would take much more space to do justice to the authors.)

\section{Summary and conclusions}

This chapter presents a first and abstract-general exposition of the capitalist economy, focusing on its mode of production. The starting point is its appearance in empirical reality of the outward bifurcation - the institutional separation - between, on the one hand, households that are the site of consumption and of the pro-creation of labour-capacity and, on the other hand, privately owned enterprises in which the production is carried out. This constellation is

57 Its problems are most transparent in Marx's draft text for Capital, Volume II, Part Two, on the 'Turnover of Capital'. 
posited as dissociative even if we know that in reality the bifurcated poles are in some way bridged. The object of the exposition is to comprehend the range of this dissociation and the extent of its actual resolution. (Division 1.)

The poles of the outward bifurcation are apparently bridged via the trade relation. However, the inherently multifaceted dimensions of goods and capacities require commensuration in terms of a common denominator. The latter derives from the everyday market 'trans-abstraction' that ascribes to goods and capacities the super-sensuous dimension of 'value' as mediated by money money, which itself has no inherent content or value. Entities are made commensurate in terms of this super-sensuous dimension that we 'know' only through money as its quantifier, a quantifier whose guise is insignificant. The market interaction so constitutes goods and capacities as commodities, that is, as dual (or inwardly bifurcated) entities - duality along the multifaceted dimensions of usability, on the one hand, and the mono-dimension of monetary value, on the other.

The monetary-value dimension and the commodification of goods and labour-capacity determine the market-interconnection of the poles, the enterprises being driven by monetary profit. The market-interconnection engenders 'merely' the duality of things and capacities. (Divisions 2-4.)

This 'mere' duality becomes serious when the production in enterprises is considered in face of the mono-drive of monetary profit. The latter then is concretely dominant in respect of what is (not) produced and how it is (not) produced. It affects what counts and what does not count. Astonishingly the super-sensuousness of the monetary value of things and capacities affects their sensuous being and coming into being. As such sensuous physical-technical production becomes a mere instrument for valorisation - the production of monetary value, or value-added. So much for the general form of the capitalist production process. (Subdivision 5 A.)

However, this general form lacks a criterion for determining what instrumental guise - namely what physical commodity and what physical technique - is most efficacious for profit.

This requires: first, a common measure for the amount of investments, which is 'capital'; secondly, the grasping of time of investment as 'production time'; and thirdly, a measure for the duration of capital investment in terms of a standard time, which is the calendar year. The profit - more precisely the surplus-value - gained during a year, over a year's capital investment, that is, the 'rate of integral profit', delivers the criterion. (Metaphorically: the end 'omega'.) $)^{58}$ 
Given the enterprises' profit drive, the production must encompass the equivalent of the value-added component of profit. Even if the general form of the capitalist production process is dominated by monetary value and valorisation, it necessarily also remains a physical-technical process, hence it remains a dual process. Within this duality the main distinction between means of production and labour-capacity (L) is that the former are inherently static elements, whereas labour-capacity in operation, that is labour $\left(\mathrm{L}^{\alpha}\right)$, is the active element. Means of production can merely be operated or not be operated. Labourcapacity operates means of production, and so exerts labour at the level of some productive power $(\alpha)$, including a component of the intensity of labour. At zero intensity (in effect a strike) there is no production, either physical or through valorisation. Hence, along with its physical production, labour creates the (yet ideal) value and so also the surplus-value (integral profit). Thus alpha $(\alpha)$ is the 'parameter' of the productive transformation: the productive power of labour in both these aspects. (Metaphorically: the beginning 'alpha'.) ${ }^{59}$

Whereas capital constrains the possible production, the power of labour $(\alpha)$ determines how much output is actually produced. The implication is that labour - more specifically, the actual productive power of labour - is the unique source of valorisation. Nevertheless this productive power is always based on an actual technique of production. Technology and its application in specific techniques is inevitably the result of social labour.

Labour being the creator of value-added, it is merely 'compensated' by the wage, the enterprise appropriating the surplus-value, that is, the difference between value-added and the wage. Surplus-value is generally the source of the growth of capital. Because labour is the unique source of valorisation and hence of surplus-value, labour essentially produces the equivalent of its own wage as well as that of the growth of capital. Hence labour essentially produces capital. ${ }^{60}$ (Subdivision 5 B.)

Herewith, in sum, the enterprises' dissociative production appears as resolved (sublated) in labour's production of surplus-value, which thereby - with the enterprises appropriating the surplus-value - satisfies the enterprises' driving force. Although some major problems for the reproduction of the capitalist bifurcated economy now seem resolved, we will see in the coming chapters that the resolution reached so far requires further conditions to be met. (Subdivision ${ }_{5} \mathrm{C}$.)

59 Apocalypse 21:6.

6o Thus the labour comprehending the process might claim to be the source of 'Alpha and Omega, the beginning and the end' (Apocalypse 21:6). 


\section{List of figures chapter 1}

Scheme 1.1 The capitalist mode of production (outline Chapter 1 ) 30

1§1. Dissociated outward bifurcation into households and privately owned enterprises

Table 1.2 Particular forms of activity pertaining to the outwardly bifurcated capitalist economy - specific to its mode of production 35

1§11. Dominance of the monetary valorisation process over the technical process: the inwarded drive for profit

Scheme 1.3 Linear exposition along with reinforcing simultaneity of moments: ${ }_{1} D_{3-1} D_{5} A\left(1 \S 5^{-1} \S 11\right) \quad 6$ o

1§13. Capital and time - the rate of integral profit and standard time

Figure 1.4 Simplified balance sheet of an enterprise (per some specific date) 65

1§14. Appropriation of the productive power of labour

Table 1.5 Summary of the distinction between market and production related concepts of labour $\quad 72$ 